\title{
The Effects of Quantitative Easing on Interest Rates: Channels and Implications for Policy
}

ABSTRACT We evaluate the effect of the Federal Reserve's purchase of long-term Treasuries and other long-term bonds (QE1 in 2008-09 and QE2 in 2010-11) on interest rates. Using an event-study methodology, we reach two main conclusions. First, it is inappropriate to focus only on Treasury rates as a policy target, because quantitative easing works through several channels that affect particular assets differently. We find evidence for a signaling channel, a unique demand for long-term safe assets, and an inflation channel for both QE1 and QE2, and a mortgage-backed securities (MBS) prepayment channel and a corporate bond default risk channel for QE1 only. Second, effects on particular assets depend critically on which assets are purchased. The event study suggests that MBS purchases in QE1 were crucial for lowering MBS yields as well as corporate credit risk and thus corporate yields for QE1, and Treasuriesonly purchases in QE2 had a disproportionate effect on Treasuries and agency bonds relative to MBSs and corporate bonds, with yields on the latter falling primarily through the market's anticipation of lower future federal funds rates.

$\mathrm{T}$

he Federal Reserve has recently pursued the unconventional policy of purchasing large quantities of long-term securities, including Treasury securities, agency securities, and agency mortgage-backed securities (MBS). The stated objective of this quantitative easing (QE) is to reduce long-term interest rates in order to spur economic activity (Dudley 2010). There is significant evidence that $\mathrm{QE}$ policies can alter long-term interest rates. For example, Joseph Gagnon and others (2010) present an event study of QE1 that documents large reductions in interest rates on dates 
associated with positive QE announcements. Eric Swanson (2011) presents confirming event-study evidence from the 1961 Operation Twist, where the Federal Reserve purchased a substantial quantity of long-term Treasuries. Apart from the event-study evidence, there are papers that look at lower-frequency variation in the supply of long-term Treasuries and document its effects on interest rates (see, for example, Krishnamurthy and Vissing-Jorgensen 2010). ${ }^{1}$

Although it is clear from this body of work that QE lowers medium- and long-term interest rates, the channels through which this reduction occurs are less clear. The main objective of this paper is to evaluate these channels and their implications for policy. We review the principal theoretical channels through which QE may operate. We then examine the event-study evidence with an eye toward distinguishing among these channels, studying a range of interest rates and drawing in additional facts from various derivatives prices to help separate the channels. We furthermore supplement previous work by adding evidence from QE2 and evidence based on intraday data. Studying intraday data allows us to document price reactions and trading volume in the minutes after the main announcements, thus increasing confidence that any effects documented in daily data are due to these announcements.

It is necessary to understand the channels of operation in order to evaluate whether a given QE policy was successful. Here is an illustration of this point: Using annual data back to 1919, Krishnamurthy and VissingJorgensen (2010) present evidence for a channel whereby changes in longterm Treasury supply drive the safety premiums on long-term assets with near-zero default risk. Our findings in that paper suggest that QE policy that purchases very safe assets such as Treasuries or agency bonds should work particularly to lower the yields of bonds that are extremely safe, such as Treasuries, agency bonds, and high-grade corporate bonds. But even if a policy affects Treasury interest rates, such rates may not be the most policy-relevant ones. A lot of economic activity is funded by debt that is not as free of credit risk as Treasuries or other triple-A bonds. For example, about 40 percent of corporate bonds are rated Baa or lower (for which our earlier work suggests that the demand for assets with near-zero default risk does not apply). Similarly, MBSs issued to fund household mortgages are less safe than Treasuries because of the substantial prepayment risk

1. Other papers in the literature that have examined Treasury supply and bond yields include Bernanke, Reinhart, and Sack (2004), Greenwood and Vayanos (2010), D'Amico and King (2010), Hamilton and Wu (2010), and Wright (2011). 
involved. Whether yields on these less safe assets fall as much as those on very safe assets depends on whether QE succeeds in lowering default risk or the default risk premium (for corporate bonds) and the prepayment risk premium (for MBSs).

One of the principal findings of this paper is that the large reductions in mortgage rates due to QE1 appear to be driven partly by the fact that QE1 involved large purchases of agency-backed MBSs (thus reducing the price of mortgage-specific risk). In contrast, for QE2, which involved only Treasury purchases, we find a substantial impact on Treasury and agency bond rates, but smaller effects on MBS and corporate rates. Furthermore, we find a substantial reduction in default risk or the default risk premium for corporate bonds only for QE1, suggesting that the MBS purchases in QE1 may also have helped drive down corporate credit risk and thus corporate yields (possibly via the resulting mortgage refinancing boom and its impact on the housing market and consumer spending). The main effect on corporate bonds and MBSs in QE2 appears to have been through a signaling channel, whereby financial markets interpreted QE as signaling lower federal funds rates going forward. This finding for QE2 raises the question of whether the main impact of a Treasuries-only QE may have been achievable with a statement by the Federal Reserve committing to lower federal funds rates, that is, without the Fed putting its balance sheet at risk in order to signal lower future rates.

The next section of the paper lays out the channels through which QE may be expected to operate. We then, in sections II and III, present results of event studies of QE1 and QE2 to evaluate the channels. We document that QE worked through several channels. First, a signaling channel (reflecting the market inferring information from $\mathrm{QE}$ announcements about future federal funds rates) significantly lowered yields on all bonds, with the effects depending on bond maturity. Second, the impact of QE on MBS rates was large when QE involved MBS purchases, but not when it involved only Treasury purchases, indicating that another main channel for QE1 was to affect the equilibrium price of mortgage-specific risk. Third, default risk or the default risk premium for corporate bonds fell for QE1 but not for QE2, contributing to lower corporate rates. Fourth, yields on mediumand long-maturity safe bonds fell because of a unique clientele for safe nominal assets, and Federal Reserve purchases reduced the supply of such assets and hence increased the equilibrium safety premium. Fifth, evidence from inflation swap rates and Treasury inflation-protected securities (TIPS) shows that expected inflation increased as a result of both QE1 and QE2, implying larger reductions in real than in nominal rates. Section IV presents 
regression analysis building on our previous work in Krishnamurthy and Vissing-Jorgensen (2010) to provide estimates of the expected effects of QE on interest rates via the safety channel. Section V concludes.

\section{Channels}

We begin by identifying and describing the various channels through which QE might operate.

\section{I.A. Signaling Channel}

Gauti Eggertsson and Michael Woodford (2003) argue that nontraditional monetary policy can have a beneficial effect in lowering long-term bond yields only if such policy serves as a credible commitment by the central bank to keep interest rates low even after the economy recovers (that is, lower than what a Taylor rule may call for). James Clouse and others (2000) argue that such a commitment can be achieved when the central bank purchases a large quantity of long-duration assets in QE. If the central bank later raises rates, it takes a loss on these assets. To the extent that the central bank weighs such losses in its objective function, purchasing longterm assets in QE serves as a credible commitment to keep interest rates low. Furthermore, some of the Federal Reserve's announcements regarding QE explicitly contain discussion of its policy on future federal funds rates. Markets may also infer that the Federal Reserve's willingness to undertake an unconventional policy like QE indicates that it will be willing to hold its policy rate low for an extended period.

The signaling channel affects all bond market interest rates (with effects depending on bond maturity), since lower future federal funds rates, via the expectations hypothesis, can be expected to affect all interest rates. We examine this channel by measuring changes in the prices of federal funds futures contracts, as a guide to market expectations of future federal funds rates. ${ }^{2}$ The signaling channel should have a larger impact on intermediatematurity than on long-maturity rates, since the commitment to keep rates low lasts only until the economy recovers and the Federal Reserve can sell the accumulated assets.

2. Piazzesi and Swanson (2008) show that these futures prices reflect a risk premium, in addition to such expectations. If short-term rates are low and employment growth is strong, the risk premium is smaller. To the extent that this risk premium is reduced by QE, our estimates of the signaling effect are too large. It is difficult to assess whether changes in short-term rates or employment growth due to QE have the same effect as non-policy-related changes in these variables, so we do not attempt to quantify any such bias. 


\section{I.B. Duration Risk Channel}

Dimitri Vayanos and Jean-Luc Vila (2009) offer a theoretical model for a duration risk channel. Their one-factor model produces a risk premium that is approximately the product of the duration of the bond and the price of duration risk, which in turn is a function of the amount of duration risk borne by the marginal bond market investor and this investor's risk aversion. By purchasing long-term Treasuries, agency debt, or agency MBSs, policy can reduce the duration risk in the hands of investors and thereby alter the yield curve, particularly reducing long-maturity bond yields relative to short-maturity yields. To deliver these results, the model departs from a frictionless asset pricing model. The principal departures are the assumptions that there is a subset of investors who have preferences for bonds of specific maturities ("preferred-habitat demand") and another subset who are arbitrageurs and who become the marginal investors for pricing duration risk.

An important but subtle issue in using the model to think about QE is whether the preferred-habitat demand applies narrowly to a particular asset class (for example, only to the Treasury market) or broadly to all fixedincome instruments. For example, if some investors have a special demand for 10-year Treasuries, but not for 10-year corporate bonds (or mortgages or bank loans), then the Federal Reserve's purchase of 10-year Treasuries can be expected to affect Treasury yields more than corporate bond yields. Vayanos and Vila (2009) do not take a stand on this issue. Robin Greenwood and Vayanos (2010) offer evidence for how a change in the relative supply of long-term versus short-term Treasuries affects the yield spread between them. This evidence also does not settle the issue, because it focuses only on Treasury data.

Recent studies of QE have interpreted the model as being about the broad fixed-income market (see Gagnon and others 2010), and that is how we proceed. Under this interpretation, the duration risk channel makes two principal predictions:

- QE decreases the yield on all long-term nominal assets, including Treasuries, agency bonds, corporate bonds, and MBSs.

-The effects are larger for longer-duration assets.

\section{I.C. Liquidity Channel}

The QE strategy involves purchasing long-term securities and paying for them by increasing reserve balances. Reserve balances are a more liquid asset than long-term securities. Thus, QE increases the liquidity in the hands 
of investors and thereby decreases the liquidity premium on the most liquid bonds.

It is important to emphasize that this channel implies an increase in Treasury yields. That is, it is commonly thought that Treasury bonds carry a liquidity price premium, and that this premium was high during particularly severe periods of the crisis. An expansion in liquidity can be expected to reduce such a liquidity premium and increase yields. This channel thus predicts that

- QE raises yields on the most liquid assets, such as Treasuries, relative to other, less liquid assets.

\section{I.D. Safety Channel}

Krishnamurthy and Vissing-Jorgensen (2010) offer evidence that there are significant clienteles for long-term safe (that is, near-zero-default-risk) assets, whose presence lowers the yields on such assets. The evidence comes from relating the spread between Baa-rated and Aaa-rated corporate bonds (or agency bonds) to variation in the supply of long-term Treasuries, over the period from 1925 to 2008 . In that paper we report that when there are fewer long-term Treasuries in the market, so that there are fewer longterm safe assets to meet clientele demands, the spread between Baa and Aaa bonds rises. The safety channel can be thought of as describing a preferred habitat of investors, but applying only to the space of safe assets.

The increase in yield spreads between near-zero-default-risk assets and riskier assets generated by the clientele demand for long-term safe assets is not the same as the risk premium in a standard asset pricing model; rather, it reflects a deviation from standard models. A simple way to think about investor willingness to pay extra for assets with very low default-risk is to plot an asset's price against its expected default rate. Krishnamurthy and Vissing-Jorgensen (2010) argue that this curve is very steep for low default rates, with a slope that flattens as the supply of Treasuries increases. Figure 1 illustrates the distinction. The straight line represents the value of a risky bond as determined in a consumption-based capital asset pricing model (C-CAPM). As default risk rises, the price of the bond falls. The distance from this line up to the lower of the two curves illustrates the safety premium; for bonds that have very low default risk, the price rises as a function of the safety of the bond, more so than in a standard C-CAPM setting. The figure also illustrates the dependence of the safety premium on the supply of long-term Treasuries. The distance from the straight line to the upper curve represents the safety premium for a smaller supply of safe assets. The clientele demand shifts the premium upward because of a higher marginal 
Figure 1. The Safety Premium on Bonds with Near-Zero Default Risk

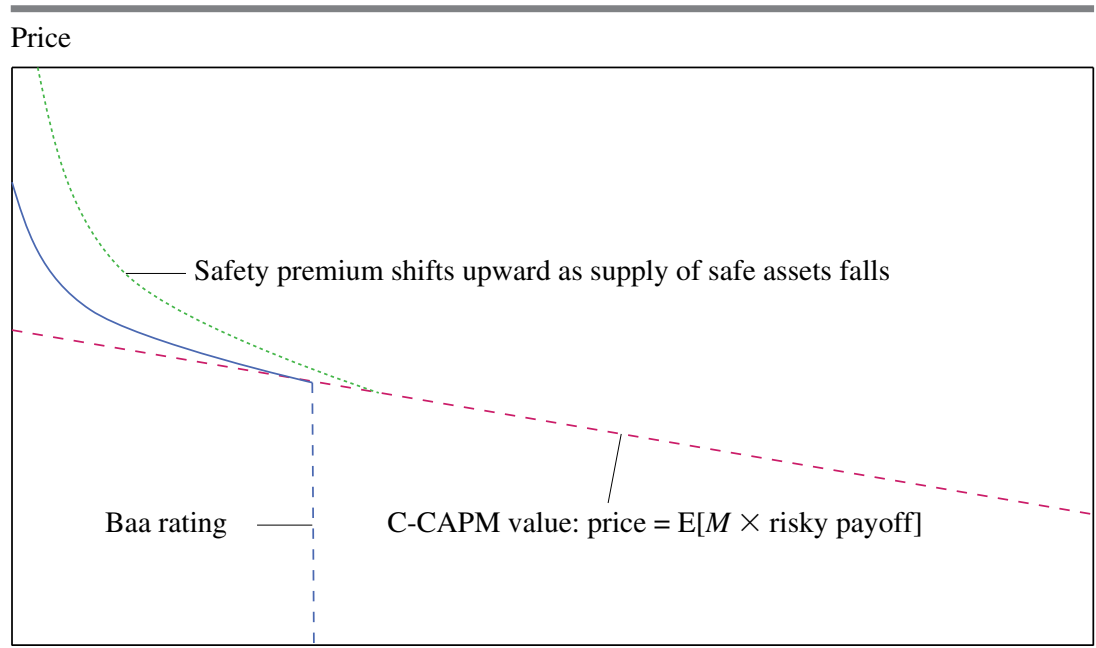

Default probability

willingness to pay for safety when supply is lower. This dependence of the premium on the supply of long-term Treasuries is how Krishnamurthy and Vissing-Jorgensen (2010) distinguish a standard risk premium explanation of defaultable bond pricing from an explanation based on clientele-driven demand for safety.

This same effect may be expected to play out in QE. However, there is a subtle issue in thinking about different asset classes in QE: Treasury and agency bonds are clearly safe in the sense of offering an almost certain nominal payment (note that the government "takeover" of Fannie Mae and Freddie Mac was announced on September 7, 2008, before QE1 and QE2, making agency bonds particularly safe during the period of QE1 and QE2); however, agency MBSs have significant prepayment risk, which means that they may not meet clientele safety demands. The safety channel thus predicts that

$-\mathrm{QE}$ involving Treasuries and agencies lowers the yields on very safe assets such as Treasuries, agencies, and possibly high-grade corporate bonds, relative to less safe assets such as lower-grade corporate bonds or bonds with prepayment risk such as MBSs.

We expect Baa bonds to be the relevant cutoff for these safety effects, for two reasons. First, such bonds are at the boundary between investmentgrade and non-investment-grade securities, so that if prices are driven by clientele demands for safety, the Baa bond forms a natural threshold. Second, 
and more rigorously, Francis Longstaff, Sanjay Mithal, and Eric Neis (2005) use credit default swap data from March 2001 to October 2002 to show that the component of yield spreads that is hard to explain by purely default risk information is about 50 basis points (bp) for Aaa- and Aa-rated bonds and about $70 \mathrm{bp}$ for lower-rated bonds, suggesting that the cutoff for bonds whose yields are not affected by safety premiums is somewhere around the A or Baa rating.

\section{I.E. Prepayment Risk Premium Channel}

QE1 involved the purchase of $\$ 1.25$ trillion of agency MBSs. Xavier Gabaix, Krishnamurthy, and Olivier Vigneron (2007) present theory and evidence that mortgage prepayment risk carries a positive risk premium, and that this premium depends on the quantity of prepayment risk borne by mortgage investors. The theory requires that the MBS market is segmented and that a class of arbitrageurs who operate predominantly in the MBS market are the relevant investors in determining the pricing of prepayment risk. This theory is similar to Vayanos and Vila's (2009) explanation of the duration risk premium and more broadly fits into theories of intermediary asset pricing (see He and Krishnamurthy 2010).

This channel is particularly about QE1 and its effects on MBS yields, which reflect a prepayment risk premium:

-MBS purchases in QE1 lower MBS yields relative to other bond market yields.

—No such effect should be present in QE2.

\section{I.F. Default Risk Channel}

Lower-grade bonds such as Baa bonds carry higher default risk than Treasury bonds. QE may affect the quantity of such default risk as well as its price (that is, the risk premium). If $\mathrm{QE}$ succeeds in stimulating the economy, one can expect that the default risk of corporations will fall, and hence Baa rates will fall. Moreover, some standard asset pricing models predict that investor risk aversion will fall as the economy recovers, implying a lower default risk premium. Finally, extensions of the intermediary pricing arguments we have offered above for pricing prepayment risk can imply that increasing financial health or increasing capital in the intermediary sector can further lower the default risk premium.

We use credit default swap (CDS) rates to evaluate the importance of a default risk channel. A credit default swap is a financial derivative used to hedge against default by a firm. The credit default swap rate measures the percentage of face value that must be paid as an annual insurance premium 
to insure against default on the bonds of a given firm. A 5-year CDS is such an insurance contract that expires in 5 years, and a 10-year CDS is one that expires in 10 years. We use these CDSs to infer default risk at different maturities.

\section{I.G. Inflation Channel}

To the extent that QE is expansionary, it increases inflation expectations, and this can be expected to have an effect on interest rates. In addition, some commentators have argued that QE may increase tail risks surrounding inflation. ${ }^{3}$ That is, in an environment where investors are unsure about the effects of policy on inflation, policy actions may lead to greater uncertainty over inflation outcomes. Others have argued that aggressive policy decreases uncertainty about inflation in the sense that it effectively combats the possibility of a deflationary spiral. Ultimately, this is an issue that can only be sorted out by data. We propose looking at the implied volatility on interest rate options, since a rise in inflation uncertainty will plausibly also lead to a rise in interest rate uncertainty and implied volatility. The inflation channel thus predicts that

- QE increases the fixed rate on inflation swaps as well as inflation expectations as measured by the difference between nominal bond yields and TIPS yields.

-QE may increase or decrease interest rate uncertainty as measured by the implied volatility on swaptions.

Two explanations are in order. First, a (zero-coupon) inflation swap is a financial instrument used to hedge against a rise in inflation. The swap is a contract between a fixed-rate payor and a floating-rate payor that specifies a one-time exchange of cash at the maturity of the contract. The floatingrate payor pays the realized cumulative inflation, as measured using the consumer price index, over the life of the swap. The fixed-rate payor makes a fixed payment indexed by the fixed rate that is contracted at the initiation of the swap agreement. In an efficient market, the fixed-rate payment thus measures the expected inflation rate over the life of the swap.

Second, a swaption is a financial derivative on interest rates. The buyer of a call swaption earns a profit when the interest rate rises relative to the strike on the swaption. As with any option, following the Black-Scholes model, the expected volatility of interest rates enters as an important input

3. See Charles Calomiris and Ellis Tallman, "In Fed's Monetary Targeting, Two Tails Are Better than One," Bloomberg Business Week, November 17, 2010 (www.businessweek.com/ investor/content/nov2010/pi20101117_644007.htm). 
for pricing the swaption. The implied volatility is the expected volatility of interest rates as implied from current market prices of swaptions.

\section{I.H. Summary}

The channels we have discussed and our empirical approach can be summarized with a few equations. Suppose that we are interested in the real yield on a $T$-year long-term, risky, illiquid asset such as a corporate bond or an MBS. Denote this yield by $r_{\text {risky, illiq, long-term }}$. Also, denote the expected average interest rate over the next $T$ years on short-term safe and liquid nominal bonds as $\mathrm{E}\left[i_{\text {safe, liq, short-term }}\right]$, and the expected inflation rate over the same period as $\pi^{e}$. Then we can decompose the long-term real yield as

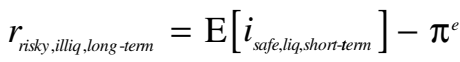

$$
\begin{aligned}
& + \text { Duration } \times P_{\text {DurationRisk }} \\
& + \text { Illiquidity } \times P_{\text {Liquidity }} \\
& + \text { Lackofsafety } \times P_{\text {Safery }} \\
& + \text { DefaultRisk } \times P_{\text {Defaultisk }} \\
& + \text { PrepaymentRisk } \times P_{\text {Prepaymentisk }} .
\end{aligned}
$$

Each line in this equation reflects a channel we have discussed. The first line gives the expectations hypothesis terms: the long-term real yield reflects the expected average future real interest rate. The signaling channel for QE may affect $r_{\text {risky,iliq, long-term }}$ through the first line (via the term $\left.\mathrm{E}\left[i_{\text {safe, liq,short-term }}\right]\right)$. Expected inflation can also be expected to affect longterm real rates. The term in the second line reflects a duration risk premium that is a function of duration and the price of duration risk, as explained above. This decomposition is analogous to the textbook treatment of the CAPM, where the return on a given asset is decomposed as the asset's beta multiplied by the market risk premium. The term in the third line is the illiquidity premium we have discussed, which is likewise related to an asset's illiquidity multiplied by the market price of liquidity. The next terms reflect the safety premium (the extra yield on the nonsafe bond because it lacks the extreme safety of a Treasury bond), a premium on default risk, and for the case of MBSs, a premium on prepayment risk.

The equation makes clear that a given interest rate can be affected by $\mathrm{QE}$ through a variety of channels. It is not possible to examine the change in, say, the Treasury rate alone to conclude how much $\mathrm{QE}$ affects interest rates more broadly, because different interest rates are affected by $\mathrm{QE}$ in different ways. 
Our main empirical methodology for examining the various channels can be thought of as a difference-in-differences approach supplemented with information from derivatives. For example, in asking whether there is a liquidity channel that may affect interest rates, we consider the yield spread between a long-term agency bond and a long-term Treasury bond and measure how this yield spread changes over the relevant QE event. The yield decomposition from equation 1 for each of these bonds is identical, except for the term involving liquidity. That is, these bonds have the same duration, safety, default risk, and so forth, but the Treasury bond is more liquid than the agency bond. Thus, the difference in yield changes between these bonds isolates a liquidity channel. We examine how this yield spread changes over the QE event dates. We take this difference-in-differences approach in evaluating the liquidity, safety, duration risk premium, and prepayment risk channels. In addition, in some cases we use derivatives prices, which are affected by only a single channel, to separate out the effect of a particular channel. This is how we use the federal funds futures contracts, the CDS rates, the inflation swap rates, and the implied volatility on interest rate options.

\section{Evidence from QE1}

This section presents data from the QE1 event study and analyzes the channels through which QE1 operated. All data used throughout the paper are described in detail in the online data appendix. ${ }^{4}$

\section{II.A. Event Study}

Gagnon and others (2010) provide an event study of QE1 based on the announcements of long-term asset purchases by the Federal Reserve in the period from late 2008 to 2009. QE1 included purchases of MBSs, Treasury securities, and agency securities. Gagnon and others (2010) identify eight event dates beginning with the November 25, 2008, announcement of the Federal Reserve's intent to purchase $\$ 500$ billion of agency MBSs and $\$ 100$ billion of agency debt and continuing into the fall of 2009 . We focus on the first five of these event dates (November 25, December 1, and December 16, 2008, and January 28 and March 18, 2009), leaving out three later event dates on which only small yield changes occurred.

4. Online appendixes for all papers in this volume may be accessed at the Brookings Papers website, www.brookings.edu/economics/bpea.aspx, under "Past Editions." 
There was considerable turmoil in financial markets from the fall of 2008 to the spring of 2009, which makes inference from an event study somewhat tricky. Some of the assets we consider, such as corporate bonds and CDSs, are less liquid than Treasuries. During a period of low liquidity, the prices of such assets may react slowly to an announcement. We deal with this issue by presenting 2-day changes for all assets (from the day before to the day after the announcement). In the data, for high-liquidity assets such as Treasuries, 2 -day changes are almost the same as 1-day changes. For low-liquidity assets, the 2-day changes are almost always larger than the 1-day changes.

The second issue that arises is that we cannot be sure that the identified events are in fact important events, or the dominant events for the identified event day. That is, other significant economic news arrives during the period and potentially creates measurement error problems for the event study. To increase our confidence that the QE1 announcements were the dominant news on the five event dates we study, we graph intraday movements in Treasury yields and trading volume for each of the QE1 event dates. Figure 2, which is based on data from BG Cantor, plots data for the on-the-run 10-year Treasury bond at each date. The yields graphed are minute-by-minute averages, and trading volumes are total volume by minute. The vertical lines indicate the minutes of the announcements, defined as the minute of the first article covering the announcement in Factiva. These graphs show that the events identify significant movements in Treasury yields and Treasury trading volume and that the announcements do appear to be the main piece of news coming out on the event days, especially on December 1, 2008, December 16, 2008, and March 18, 2009. For November 25, 2008, and January 28, 2009, the trading volume graphs also suggest that the announcements are the main events, but the evidence from the yield graphs for those days is more mixed.

Although it is likely that these five dates are the most relevant event dates, it is possible that there are other "true" event dates that we have omitted. How does focusing on too limited a set of event dates affect inference? For the objective of analyzing through which channels QE operates, omitting true event dates reduces the power of our tests but does not lead to any biases (whereas including irrelevant dates could distort inference about the channels). ${ }^{5}$ For estimating the overall effect of QE, omitting potentially relevant dates could lead to an upward or a downward bias, depending on how the events on the omitted dates affected the market's perception of the probability or the magnitude of QE.

5. We thank Gabriel Chodorow-Reich for clarifying this point. 
Figure 2. Intraday Yields and Trading Volumes on QE1 Event Days ${ }^{\mathrm{a}}$

Nov. 25, 2008

Percent per year

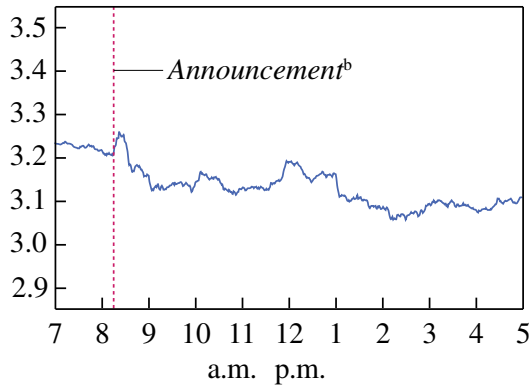

Time of day

Dec. 16, 2008

Percent per year

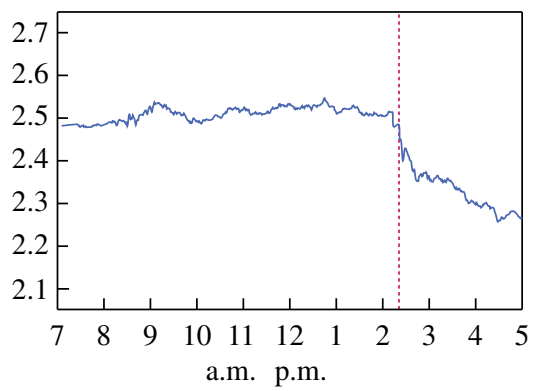

Time of day

Mar. 18, 2009

Percent per year

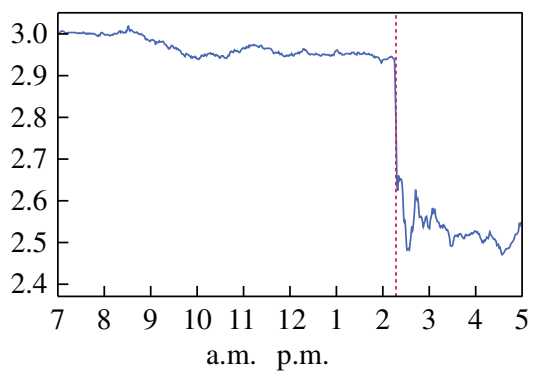

Time of day
Yields

Percent per year

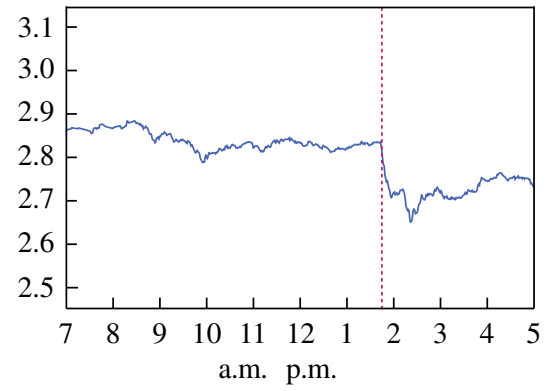

Time of day

Jan. 28, 2009

Percent per year

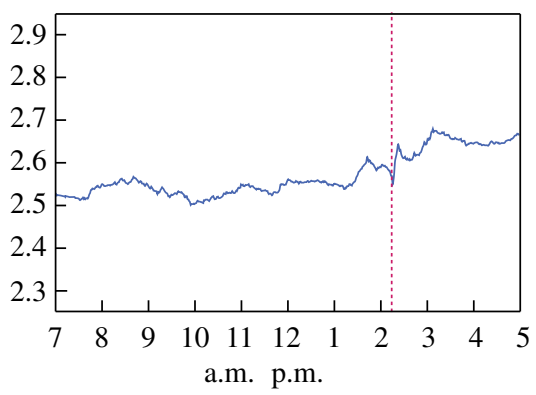

Time of day 
Figure 2. Intraday Yields and Trading Volumes on QE1 Event Days ${ }^{\mathrm{a}}$ (Continued)

Nov. 25, 2008

Million dollars of face value

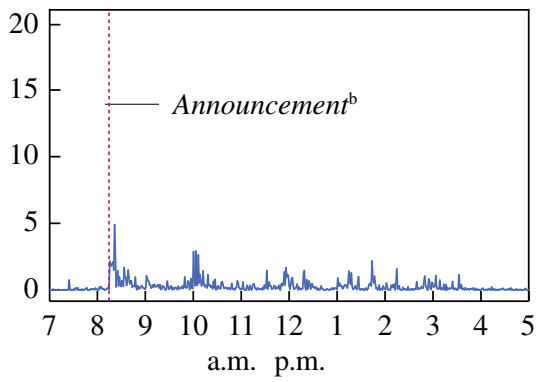

Time of day

Dec. 16, 2008

Million dollars of face value

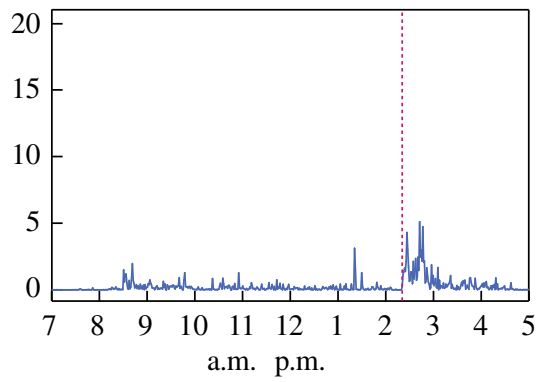

Time of day

Mar. 18, 2009

Million dollars of face value

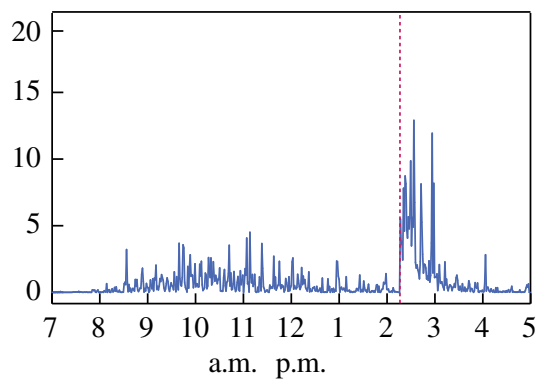

Time of day
Dec. 1, 2008

Million dollars of face value

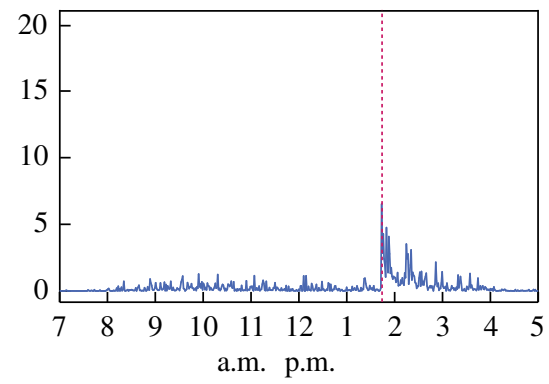

Time of day

Jan. 28, 2009

Million dollars of face value

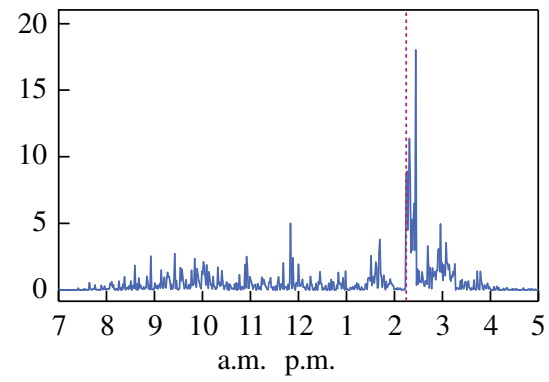

Time of day

Source: BG Cantor data.

a. Yields and trading volumes are minute-by-minute averages and total volume by minute, respectively, for the on-the-run 10-year bond on the indicated dates.

b. Minute of the appearance in Factiva of the first article covering the QE-related announcement. 
Table 1 presents data on 2-day changes in Treasury, (noncallable) agency, and agency MBS yields around the main event-study dates, spanning the period from November 25, 2008 (the 2-day change from November 24 to November 26), to March 18, 2009 (the 2-day change from March 17 to March 19). Over this period it became evident from announcements by the Federal Reserve that the government intended to purchase a large quantity of long-term securities. Across the five event dates, interest rates on long-term bonds fell across the board, consistent with a contractionof-supply effect. We now consider the channels through which the supply effect may have worked.

In all the tables in this paper we provide tests of the statistical significance of the interest rate changes or changes in derivatives prices, focusing on the total change shown in the last row of each table (for QE1 and QE2 separately). Specifically, we test whether changes on QE announcement days differ from changes on other days. To do this, we regress the daily changes for the variable in question on six dummies: a dummy for whether there was a QE1 announcement on this day, a dummy for whether there was a QE1 announcement on the previous day, a dummy for whether there was a QE2 announcement on this day, a dummy for whether there was a QE2 announcement on the previous day, a dummy for whether there was a QE3 announcement on this day, and a dummy for whether there was a QE3 announcement on the previous day. By "QE3" we refer to the Federal Reserve's announcement in its Federal Open Market Committee (FOMC) statement on September 21, 2011; this event happened after the Brookings Panel conference at which this paper was presented, but we analyze it briefly below. This regression is estimated on daily data from the start of 2008 to the end of the third quarter of 2011, using ordinary least squares estimation but with robust standard errors to account for heteroskedasticity. $F$ tests for the QE dummy coefficients being zero are then used to assess statistical significance. When testing for statistical significance of 2-day changes, the $F$ test is a test of whether the sum of the coefficient on the QE dummy (QE1 or QE2) and the coefficient on the dummy for a $\mathrm{QE}$ announcement (QE1 or QE2) on the previous day is equal to zero. When testing for statistical significance of 2-day changes in CDS rates, we follow a slightly different approach, described below, because of the way our CDS rate changes are constructed.

\section{II.B. Signaling Channel}

Figure 3 graphs the yields on the monthly federal funds futures contract, for contract maturities from March 2009 to October 2010. The preannouncement 


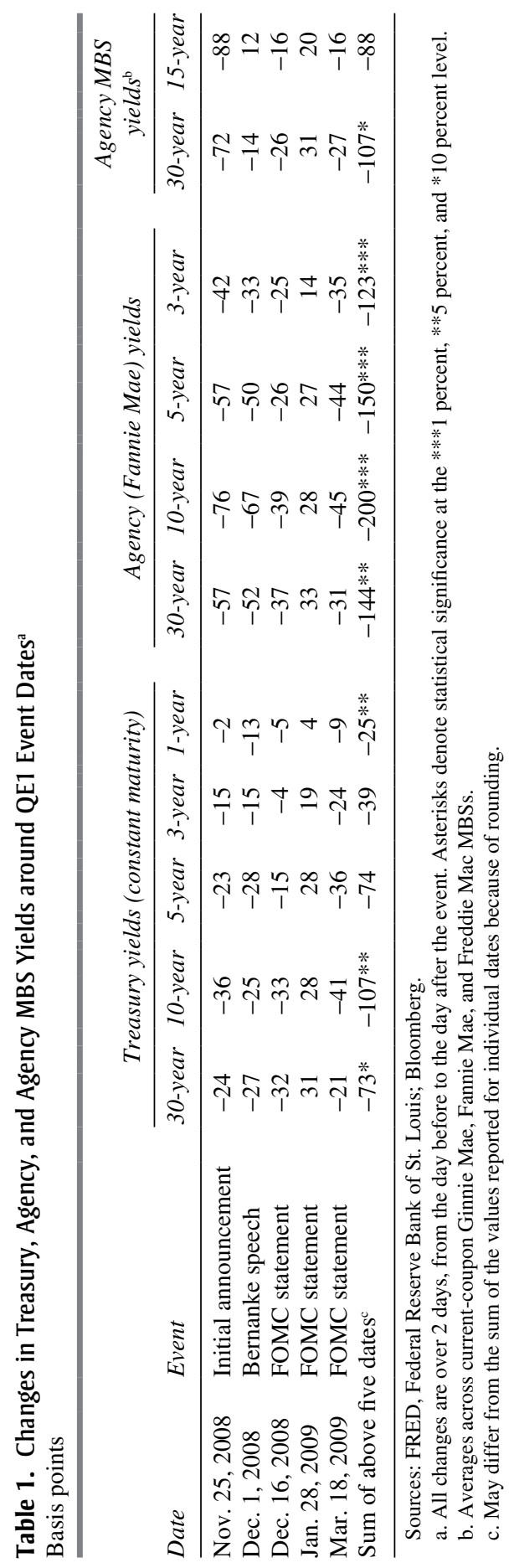


Figure 3. Yield Curves Calculated from Federal Funds Futures before and after QE1 Event Days

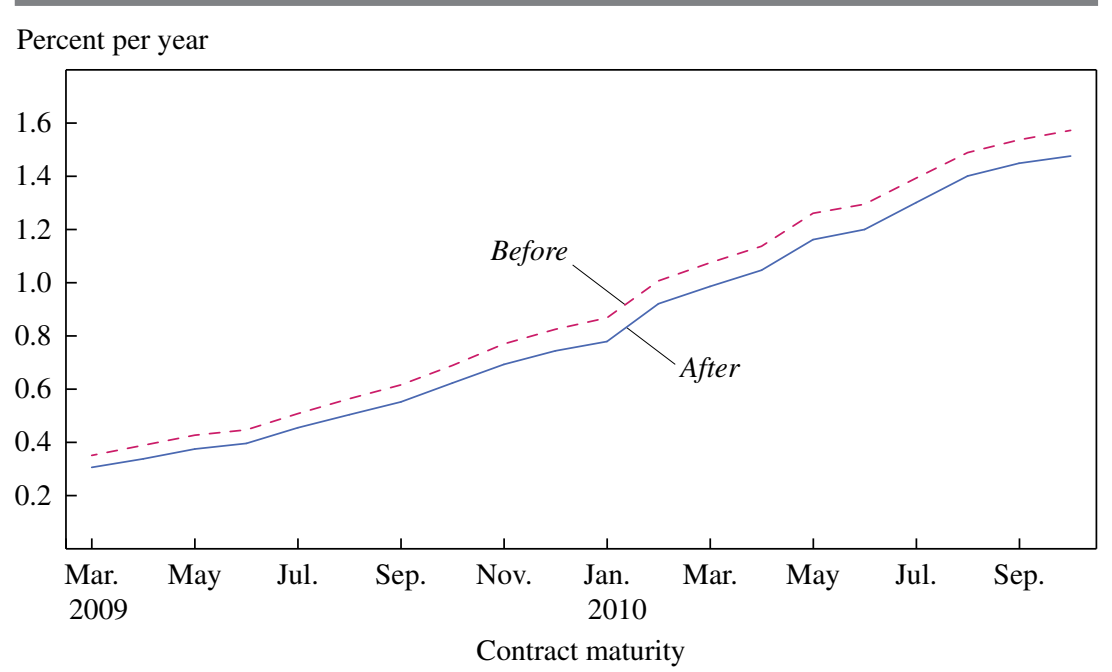

Source: Bloomberg data.

a. Yields are computed the day before each QE1 event date and again the day after. All the before-event yields are then averaged across events, and likewise for the after-event yields.

average yield curve is computed on the day before each of the five QE1 events and then averaged across these dates. The postannouncement average yield curve is computed likewise based on the five days after the QE1 event dates. Dividing the downward shift from the pre- to the postannouncement average yield curve by the slope of the initial average yield curve, and multiplying the result by the number of event dates, indicates how much the policy shifted the rate cycle forward in time. Evaluating the forward shift at the point and slope of the March 2010 contract, we find that the total effect of the five QE announcements is to shift anticipated rate increases later by 6.3 months. This effect is consistent with an effect through the signaling channel whereby the Federal Reserve's portfolio purchases (as well as direct indications of the stance of policy in the relevant Fed announcements) signal a commitment to keep the federal funds rate low.

Table 2 reports the 1- and 2-day changes in the yields of the 3rd-month, 6th-month, 12th-month, and 24th-month futures contracts across the five event dates. We aggregate by, for example, the 3rd month rather than a given contract month (for example, March), because it is more natural to think of the information in each QE announcement as concerning how 
Table 2. Changes in Federal Funds Futures Yields around QE1 and QE2 Event Dates ${ }^{\mathrm{a}}$ Basis points

\begin{tabular}{lcccc} 
& \multicolumn{4}{c}{ Federal funds futures, contract maturity } \\
\cline { 2 - 5 } Date $^{\mathrm{b}}$ & $3 r$ month & 6th month & 12th month & 24th month \\
\hline QE1 $^{\mathrm{c}}$ & -6 & -5 & -8 & -16 \\
Nov. 25, 2008 & -6 & -3 & -7 & -20 \\
Dec. 1, 2008 & -13 & -15 & -10 & -11 \\
Dec. 16, 2008 & -1 & -1 & -1 & 19 \\
Jan. 28, 2009 & -2 & -4 & -8 & -11 \\
Mar. 18, 2009 & $-28^{*}$ & -27 & $-33^{* *}$ & -40 \\
Sum & & & & \\
QE2 & & & & \\
Aug. 10, 2010 & & 0 & -2 & -3 \\
$\quad$ One-day change & 0 & 0 & -3 & -8 \\
$\quad$ Two-day change & 0 & & & -8 \\
Sep. 21, 2010 & & -1 & -3 & -8 \\
$\quad$ One-day change & 0 & -1 & -3 & $-11^{* * *}$ \\
$\quad$ Two-day change & 0 & -1 & $-4 * * *$ & $-16^{* * *}$ \\
Sum & & -1 & $-5^{* * *}$ & \\
$\quad$ One-day changes & $0 * * *$ & $0 * * *$ & &
\end{tabular}

Source: Authors' calculations using Bloomberg data.

a. Asterisks denote statistical significance at the $* * * 1$ percent, $* * 5$ percent, and $* 10$ percent level.

b. See table 1 for descriptions of events on QE1 dates; QE2 dates are those of FOMC statements regarding QE2.

c. All changes in yields for QE1 are 2-day changes, from the day before to the day after the event.

d. Because our significance tests are based on comparing changes on QE announcement days with changes on other days, changes on QE announcement days of zero can be statistically significant. For the 3-month federal funds futures, changes on non-QE days were on average slightly negative. Values may differ from the sum of the values reported for individual dates because of rounding.

long from today rates will be held low (on the other hand, for plotting a yield curve it is more natural to hold the contract month fixed, as we did in figure 3). For two of the four federal funds futures contracts, the 2-day changes for QE1 announcement dates are significantly more negative than on other days. The 2-day decrease in the 24th-month contract is $40 \mathrm{bp}$.

How much of an effect can the signaling channel have on longer-term rates? The difficulty in assessing this effect is that we cannot precisely measure changes in the expected future federal funds rate for horizons over 2 years, because federal funds futures contracts do not exist for those horizons. An upper bound on the signaling effect can be found by extrapolating the 40-bp fall in the 24th-month contract to all horizons. This is an upper bound because it is clear that at longer horizons, market expectations should reflect a normalization of the current, accommodative Federal 
Reserve policy, so that signaling should not have any effect on rates at those horizons. Nevertheless, with the 40-bp number, equation 1 predicts that rates at all horizons fall by $40 \mathrm{bp}$.

A second approach to estimating the signaling effect is to build on the observation that QE shifted the path of anticipated rate hikes by about 6 months. Signaling affects long-term rates by changing the expectations term in equation $1, \mathrm{E}\left[i_{\text {safe, }, \text { lig,short-term }}\right]$. Consider the expectations term for a $T$-year bond:

$$
\mathrm{E}\left[i_{\text {safeliqu, short-erm }}\right]=\frac{1}{T} \int_{t=0}^{T} i_{t}^{f f} \mathrm{~d} t
$$

where $i_{t}^{f f}$ is the expected federal funds rate $t$ years from today. Let $i_{t, p r i o r}^{f f}$ denote the path described by the federal funds rate as expected by the market before the QE announcements. Suppose that QE policy then signals that the rate is going to be held at $i_{0, p r i o r}^{f f}$ for the next $X$ months and thereafter follow the path indicated by $i_{t, p r i o r}^{\text {ff }}$ (such that the rate at time $t$ with the policy in place is what the rate would have been $X$ months earlier absent the policy). That is, QE simply shifts an anticipated rate hike cycle later by $X$ months. Then the decrease in the expectations term for a $T$-year bond is

$$
\Delta \mathrm{E}\left[i_{\text {safe, liq.short-term }}\right]=\frac{1}{T} \int_{t=T-X / 12}^{T}\left(i_{0, p r i o r}^{\text {ff }}-i_{t, p \text { pror }}^{f f}\right) \mathrm{d} t .
$$

The first point to note from this equation is that it indicates that the signaling effect is decreasing in maturity (that is, $T$ ). Here is a rough check on how large the signaling effect can be. Suppose that $i_{0, p r i o r}^{\text {ff }}$ is zero, which is as low as the federal funds rate fell over this period. Consider the $i_{t, p \text { prior }}^{f f}$ term next. The 2-year federal funds futures contract, which is the longest contract traded, indicated a yield as high as 1.8 percent over the period from November 2008 to March 2009. But expected federal funds rates out to, say, 10 years are likely to be much higher than that. Over the QE1 period the yield curve between 10 and 30 years was relatively flat, with Treasury rates at 10 and 30 years as high as almost 4 percent. Thus, consider a value of $i_{t, p \text { prior }}^{f f}$ of 4 percent to get an upper bound on this signaling effect. Then the change for a 10 -year bond is $20 \mathrm{bp}$, and that for a 30 -year bond is about $7 \mathrm{bp}$. At the 5-year horizon, given the slope of the yield curve, $i_{t, p r i o r}^{f f}$ is lower than 4 percent. We use 3 percent, which is based on computing average forward rates between years 4 and 7 using the 3-and 7-year Treasury yields, implying a signaling effect of $30 \mathrm{bp}$ for the 5-year horizon. Our two 
ways of computing the signaling effect indicate moves in the range of 20 to 40 bp out to 10 years. This effect potentially explains the moves in the CDS-adjusted Baa rates (in table 3 below) of 41 bp (long) and 25 bp (intermediate). It can also help explain the fall in the 1-year Treasury yield of $25 \mathrm{bp}$.

On the other hand, longer-term rates move much more substantially than shorter-term rates. Yields on longer-term Treasuries and agencies fall 73 to $200 \mathrm{bp}$, much more than the 1-year yield. For the corporate bonds in table 3 below, however, there is no apparent maturity effect (for a given ratings category). Thus, to understand the more substantial movements of longterm rates, we need to look to other channels and, in particular, the safety and prepayment risk channels.

\section{II.C. Duration Risk Channel}

Consistent with the duration risk hypothesis, the yields of many longerterm bonds in table 1 fall more than the yields of shorter-maturity bonds. The exceptions here are the 30-year Treasury and agency bonds, whose yields fall less than those of the 10 -year bonds. Note that because mortgages amortize and carry prepayment risk, the duration on the 30 -year MBS is around 7 years and is thus more comparable to that of a 10-year than that of a 30-year Treasury or agency bond. The MBS duration is from Bloomberg and calculated based on the coupon rates of the MBS series and the fact that the MBSs amortize and may prepay.

There is other evidence that the duration risk channel cannot explain. There are dramatic differences in the yield changes across the different asset classes. Agency bonds, for example, experience the largest fall in yields. The duration risk channel cannot speak to these effects, as it predicts only effects that depend on bond maturity.

The corporate bond data also cannot be explained by the duration risk channel. Table 3 presents data on corporate bond yields of intermediate (around 4 years) and long (around 10 years) duration, as well as on these same yields with the impact of changes in CDS rates taken out (the durations for the corporate series are obtained from Datastream). We adjust the yield changes using CDS changes to remove any effects due to a changing default risk premium, thereby isolating duration risk premium effects.

We construct CDS rate changes by rating category as follows. We obtain company-level CDS rates from Credit Market Analysis via Datastream. We classify companies into ratings categories based on the value-weighted average rating of the company's senior debt with remaining maturity above 1 year, using bond information from the Mergent Fixed Investment Securities 


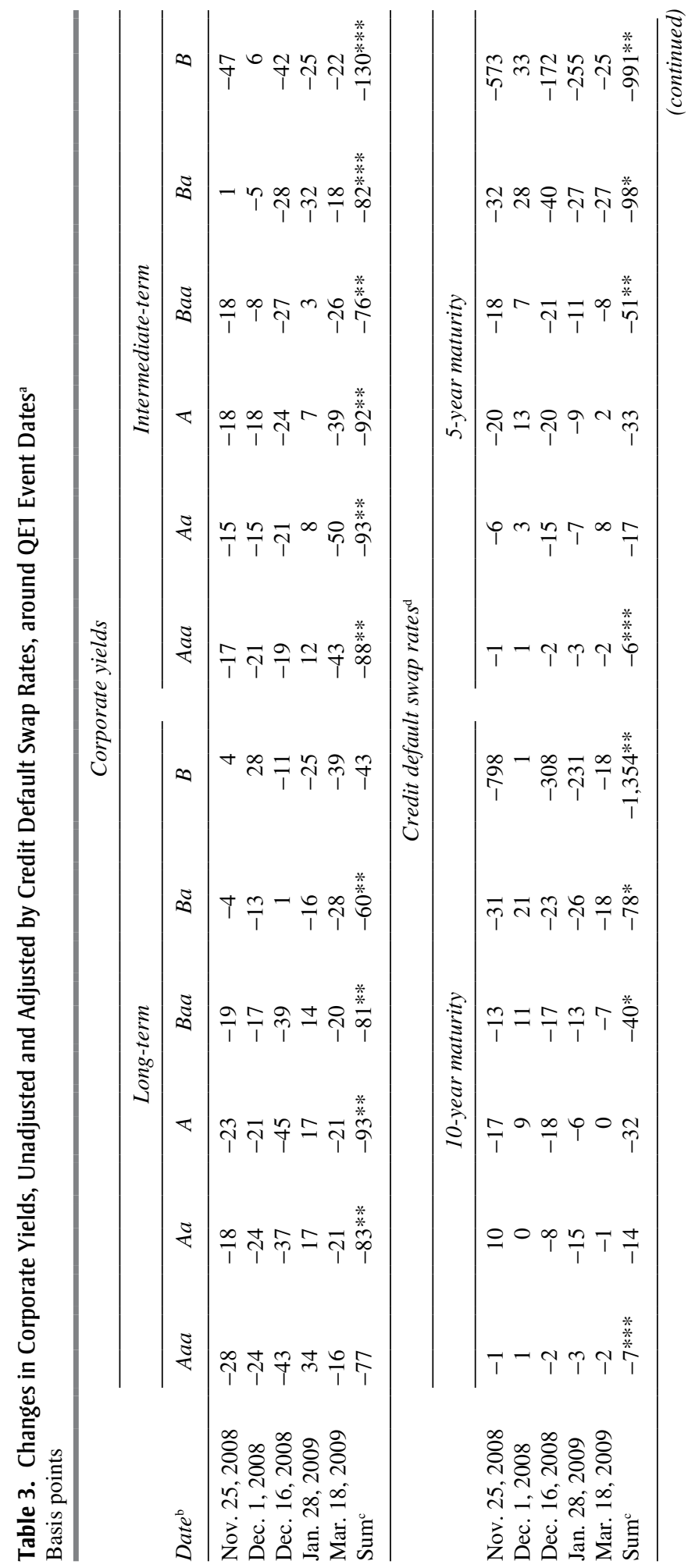




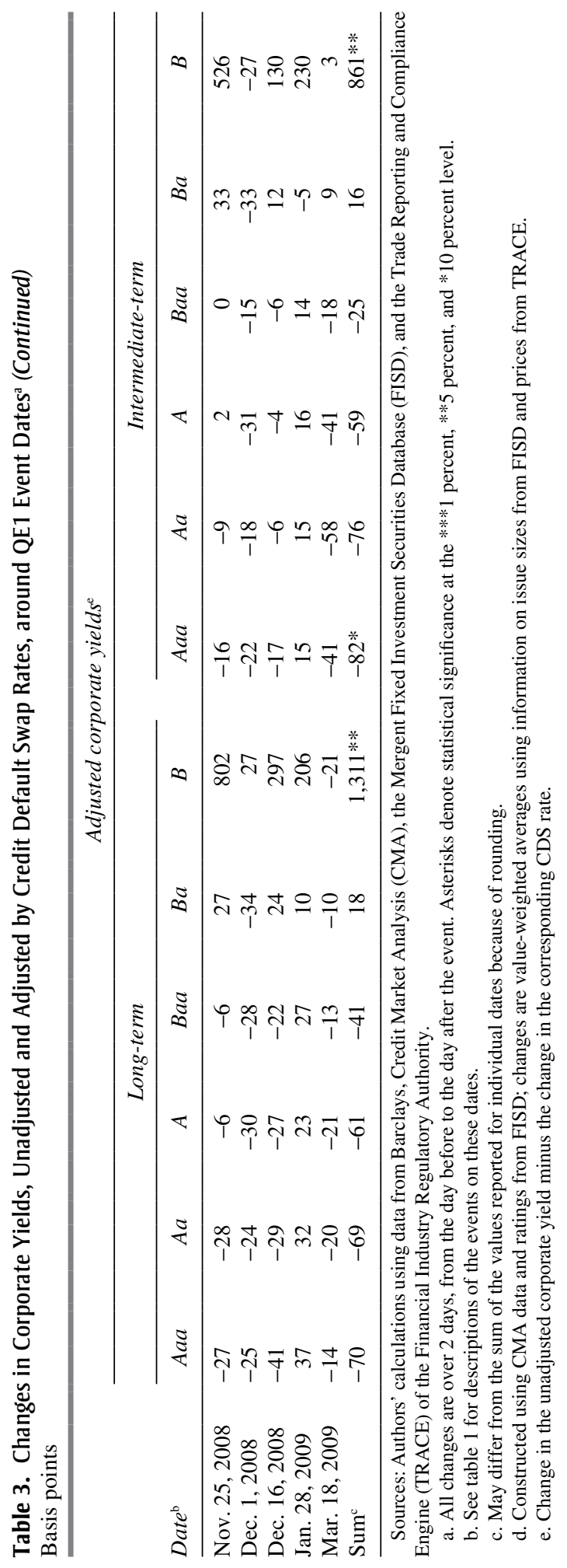


Database (FISD) and the Trade Reporting and Compliance Engine (TRACE) of the Financial Industry Regulatory Authority. For each QE date, we then calculate the company-level CDS rate change and the value-weighted average of these changes by ratings category, with weights based on the company's senior debt with remaining maturity above 1 year (weights are calculated based on market values on the day before the event day). ${ }^{6}$ The reason for calculating company-level CDS changes and then averaging across companies (call this "method 1"), as opposed to calculating average CDS rates across companies and then the change over time in the averages ("method 2"), is that we have CDS data for only a subset of companies: between 362 and 378 for each QE1 date (and around 338 for the two main QE2 dates we study below). This is likely many fewer than the number of companies for which bond yields are included in the corporate bond indexes from Barclays that we use. Therefore, if we used method 2, the CDS calculations for a given ratings category would be fairly sensitive to whether a particular company's bonds are down- or upgraded on a given day (and more so than the bond yield indexes). We avoid this problem by using method 1 , since a given time change is then calculated using CDS rates for a fixed set of companies.

A side effect of using method 1 is that the sum of two daily CDS changes for a given ratings category (each of which averages 1-day changes across companies) will not equal the 2-day CDS change for this category (calculated by averaging 2-day changes across companies). Therefore, to assess the statistical significance of 2-day CDS changes for a given ratings category, we estimate a regression where the dependent variable is the 2-day CDS change (from date $t-1$ to $t+1$ ) and the independent variables are a dummy for whether day $t$ is a QE1 announcement day and a dummy for whether day $t$ is a QE2 announcement day. To keep statistical inference simple, we use data for every second day only (as opposed to using overlapping 2-day changes). We make sure that all $\mathrm{QE}$ announcement dates are included: if a given QE date falls on a date that would otherwise not be used, we include the QE date and drop the day before and the day after the QE date. We have CDS data only up to the end of the third quarter of 2010,

6. We drop CDS rates for AIG, the large insurance firm in which the U.S. government intervened in September 2008. According to our calculations, this firm is the largest in ratings category Baa by market value of bonds outstanding and has a very high CDS rate increase on our last QE1 date. With AIG included, the 2-day CDS changes for category Baa (summed across the five QE1 dates) are $32 \mathrm{bp}$ rather than $40 \mathrm{bp}$ at the 10-year horizon and $37 \mathrm{bp}$ rather than 51 bp at the 5-year horizon. We are not sure whether AIG is still included in the Barclays bond indexes during this period, given the government's intervention in this firm. 
so we estimate the regression using data from the start of 2008 to the end of 2010Q3. We use the same regression for 2-day changes when assessing the statistical significance of 2-day yield changes adjusted for CDS changes.

The CDS adjustment makes a substantial difference in interpreting the corporate bond evidence in terms of the duration risk channel. In particular, there is a large fall in CDS rates for lower-grade bonds on the event dates, suggesting that default risk or the default risk premium fell substantially with $\mathrm{QE}$, consistent with the default risk channel (we discuss this further below). Given the CDS adjustment, the change in the yield of the Baa bond can be fully accounted for by the signaling channel. Moreover, there is no apparent pattern across long and intermediate maturities in the changes in CDS-adjusted corporate bond yields. These observations suggest that we need to look to other channels to understand the effects of QE.

\section{II.D. Liquidity Channel}

The most liquid assets in table 1 are the Treasury bonds. The liquidity channel predicts that their yields should increase with $\mathrm{QE}$, relative to the yields on less liquid bonds. Consistent with this, Treasury yields fall much less than the yields on agency bonds, which are less liquid. That is, the agency-Treasury spread falls with QE. For example, the 10-year spread falls by $200-107=93$ basis points. This is a relevant comparison because 10 -year agencies and Treasuries have similar default risk (especially since the government placed Fannie Mae and Freddie Mac into conservatorship in September 2008) and are duration matched. Thus, this spread isolates a liquidity premium. Consistent with the liquidity channel, the equilibrium price premium (yield discount) for liquidity falls substantially in economic terms. To test whether agency yield changes are statistically significantly larger than Treasury yield changes on the QE1 dates, we use the difference between agency yield changes and Treasury yield changes as the dependent variable in the regression described in section II.A. We find that this is the case, at the 5 percent level, for all maturities shown $(3,5,10$, and 30 years).

\section{II.E. Safety Channel}

The noncallable agency bonds will be particularly sensitive to the safety effect. These bonds are not as liquid as the Treasury bonds but are almost as safe. Of the channels we have laid out, (nominal) agency bond yields are mainly affected via the signaling channel, the duration risk premium channel, and the safety channel. We have argued that the duration risk premium channel is not substantial, and that the signaling channel accounts for at 
most a 40-bp decline in yields on QE1 dates. The fall in 10-year agency yields is $200 \mathrm{bp}$, the largest effect in table 1. This suggests that the impact via the safety channel on agency and Treasury yields is one of the dominant effects for QE1, at least $160 \mathrm{bp}$ for the 10-year bonds. ${ }^{7}$ To test whether agency yield changes are statistically significantly larger on the QE1 dates than the signaling channel predicts, we use the difference between agency yield changes and changes in the 24th-month federal funds futures contract yield as the dependent variable in the regression described in section II.A, and we find that this is the case, at the 5 percent level, for all maturities shown $(3,5,10$, and 30 years).

As we have just noted, the yields on Treasuries fall less than those on agencies because the liquidity effect runs counter to the safety effect, but the safety effect itself should affect Treasuries and agencies about equally.

The corporate bond evidence is also consistent with a safety effect. The CDS-adjusted yields on Aaa bonds, which are close to default free, fall much more than the CDS-adjusted yields on Baa or B bonds. The Aa and A bonds are also affected by the safety effect, but by a smaller amount, as the safety channel predicts. There is close to no effect on the non-investmentgrade bonds. ${ }^{8}$ Finally, since agencies are safer than Aaa corporate bonds, the safety channel prediction that yields on the former will fall more than those on the latter is also confirmed in the data.

\section{II.F. Prepayment Risk Channel}

Agency MBS yields fall by $107 \mathrm{bp}$ for 30 -year bonds and $88 \mathrm{bp}$ for 15 -year bonds (table 1). There are two ways to interpret this evidence. It could be due to a safety effect: the government guarantee behind these MBSs may be worth a lot to investors, so that these securities carry a safety premium. The safety premium then rises, as it does for the agency bonds, decreasing

7. When inferring the size of the safety channel from a comparison of agency yield changes and changes in federal funds futures, we are implicitly assuming that neither is affected by changes in the overall supply of liquidity in QE1. This is plausible if the following assumptions hold: that agencies are not (to a substantial extent) valued for their liquidity and do not change in price in response to a change in the supply of liquidity; that the federal funds futures we use are sufficiently far out in the future not to be affected by the high price of liquidity in the fall of 2008; and that the market expects any liquidity injected by QE1 to be withdrawn by the time of the federal funds futures contract used. The last two assumptions are plausible given that we focus on 24th-month federal funds futures.

8. The anomalously large moves in the CDS rates for the B category appear to be partly driven by Ford Motor Company bonds, perhaps related to news about the auto bailouts. If we drop Ford from the tabulation, the 5-year and 10-year CDS rates fall by $435 \mathrm{bp}$ and $496 \mathrm{bp}$, respectively. 
agency MBS yields. On the other hand, the agency MBSs carry significant prepayment risk and are unlikely to be viewed as safe in the same way as agency bonds or Treasuries (where "safety" means the almost complete certainty of nominal repayment at known dates). We think that a more likely explanation is market segmentation effects as in Gabaix, Krishnamurthy, and Vigneron (2007). The government's purchase of MBSs reduces the prepayment risk in the hands of investors, and thereby reduces MBS yields. The effect is larger for the 30-year than for the 15-year MBSs because the longer-term bonds carry more prepayment risk. ${ }^{9}$

Importantly, Andreas Fuster and Paul Willen (2010) show that the large reductions in agency MBS rates around November 25, 2008, were quickly followed by reductions in mortgage rates offered by mortgage lenders to households.

\section{II.G. Default Risk Channel}

We noted earlier from table 3 that QE appears to reduce default risk or the default risk premium, which particularly affects the interest rates on lower-grade corporate bonds. The table shows that the CDS rates of the Aaa firms do not change appreciably with QE. There is a clear pattern across the ratings, going from Aaa to B, whereby firms with higher credit risk experience the largest fall in CDS rates. In terms of statistical significance, 2-day changes in CDS rates are significantly more negative around QE1 announcement days than on other days for four of the six ratings categories. This evidence suggests that QE had a significant effect on yields through changes in default risk or the default risk premium.

\section{II.H. Inflation Channel}

The above analysis focuses on nominal interest rates (in particular, on the effects on various nominal rates relative to the nominal signaling channel benchmark). To assess effects on real rates, one needs information about the impact of QE1 on inflation expectations. Table 4 presents the relevant data.

The first four columns in the table report results for inflation swaps. For example, the column labeled "10-year" shows the change in the fixed rate on the 10-year zero-coupon inflation swap, a market-based measure of

9. The fall in MBS yields may be driven by both a reduction in prepayment risk and a reduction in the risk premium required to bear prepayment risk. This is similar to the effects on corporate bond yields, where reductions in both default risk and the default risk premium play a role. We have looked at the option-adjusted spreads on MBSs, which remove the prepayment risk effects using a model, and find that these spreads fall, suggesting that the prepayment risk premium fell. 


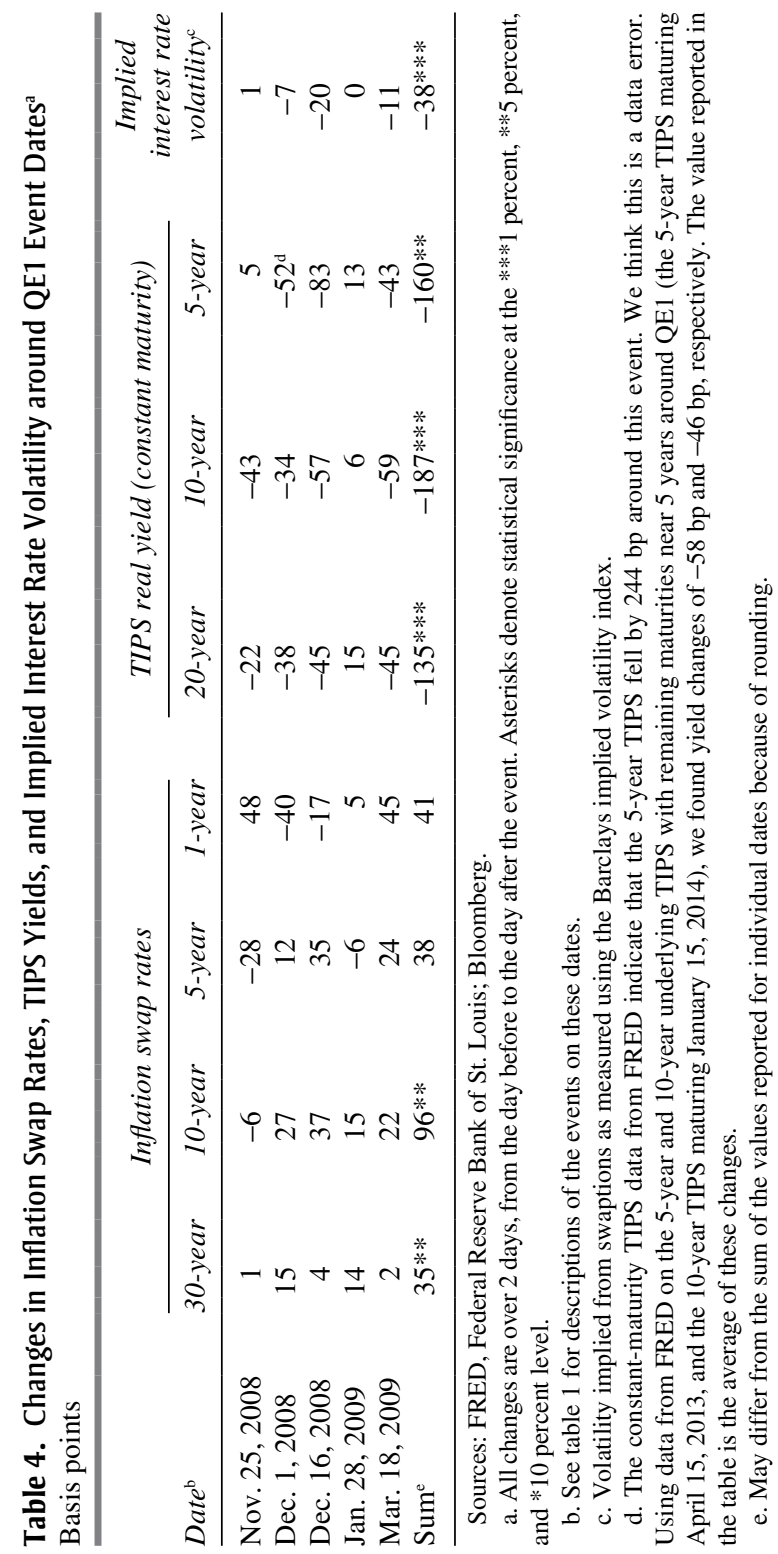


expected inflation over the next 10 years (see Fleckenstein, Longstaff, and Lustig 2010 for information on the inflation swap market). These data suggest that inflation expectations increased by between 35 and 96 bp, depending on maturity.

The next three columns present data on TIPS yields. We compare these yield changes with those for nominal bonds to evaluate the change in inflation expectations. Given the evidence of the existence of a significant liquidity premium on Treasuries, it is inappropriate to compare TIPS with nominal Treasuries. If investors' demand for safety does not apply to inflation-adjusted safe bonds such as TIPS, then the appropriate nominal benchmark is the CDS-adjusted Baa bond. On the other hand, if long-term safety demand also encompasses TIPS, then it is more appropriate to use the CDS-adjusted Aaa bond as the benchmark. We are unaware of any definitive evidence that settles the issue. From table 3, the CDS-adjusted yield on long-maturity Aaa bonds falls by $70 \mathrm{bp}$, while that for intermediate-maturity Aaa bonds falls by $82 \mathrm{bp}$; the corresponding numbers for Baa bonds are 41 and $25 \mathrm{bp}$. Matching the 70-bp change for the long-maturity Aaa bonds and the 41-bp change in the long-maturity Baa bonds to the 187-bp change in the 10-year TIPS, we find that inflation expectations increased by 117 or $146 \mathrm{bp}$, respectively, at the 10-year horizon. (Both are significant at the 1 percent level, using the same regression to test significance as used for 2-day CDS changes.) At the 5-year horizon, based on the 82-bp change in the CDS-adjusted intermediate-maturity Aaa bond, the 25-bp change in the corresponding Baa bond, and the 160-bp change in the TIPS, we find that inflation expectations increased by 78 or $135 \mathrm{bp}$ (the first is not significant and the second is significant at the 5 percent level). Benchmarking to the Aaa bond produces results more similar to those from the inflation swaps.

Together these two sets of data suggest that the impact of Federal Reserve purchases of long-term assets on expected inflation was large and positive.

We also evaluate the inflation uncertainty channel. The last column in table 4 reports data on implied volatilities from interest rate swaptions (options to enter into an interest rate swap), as measured using the Barclays implied volatility index. The underlying maturity for the swap ranges from 1 year to 30 years, involving options that expire from 3 months to 20 years. The index is based on the weighted average of implied volatilities across the different swaptions.

Average volatility by this measure over the QE1 time period is $104 \mathrm{bp}$, so the fall of $38 \mathrm{bp}$ is substantial. Thus, it appears that QE1 reduced rather than increased inflation uncertainty. 
The other explanation for this fall in volatility is segmented markets effects. MBSs have an embedded interest rate option that is often hedged by investors in the swaption market. Since QE1 involved the purchase of MBSs, investors' demand for swaptions fell, and hence the implied volatility of swaptions fell. This explanation is often the one given by practitioners for changes in swaption-implied volatilities. Notice, however, that volatility is essentially unchanged on the first QE1 event date, which is the event that drives the largest changes in MBS yields. This could indicate that the segmented markets effects are not important, with volatility instead being driven by the inflation uncertainty channel.

\section{II.I. Summary}

QE1 significantly reduced yields on intermediate- and long-maturity bonds. There is evidence that this decrease in yields, particularly on the intermediate-maturity bonds, occurred via the signaling channel, with effects on 5- to 10-year bonds ranging from 20 to $40 \mathrm{bp}$. A preferred habitat for long-term safe assets, including Treasuries, agencies, and highly rated corporate bonds, appears to have generated a large impact of QE1 on the yields on these bonds, with effects as large as $160 \mathrm{bp}$ for 10-year agency and Treasury bonds. For riskier bonds such as lower-grade corporate bonds and MBSs, QE1 had effects through a reduction in default risk or the default risk premium and a reduced prepayment risk premium. The 10-year CDS rates on Baa corporate bonds fell by $40 \mathrm{bp}$ on the QE1 dates. These effects on CDS rates and MBS pricing could be due to reductions in risk borne by the financial sector, consistent with limited intermediary capital models, or due to impacts via a mortgage refinancing boom and its impact on the housing market and consumer spending. We find little evidence of effects via the duration risk premium channel. Finally, there is evidence that $\mathrm{QE}$ substantially increased inflation expectations but reduced inflation uncertainty. The increase in expected inflation was large: 10-year expected inflation was up between 96 and $146 \mathrm{bp}$, depending on the estimation approach used, implying that real interest rates fell dramatically for a wide variety of borrowers.

Finally, note that these effects are all sizable and probably much more than one should expect in general. The period from November 2008 to March 2009 was an unusual time of financial crisis in which the demand for safe assets was heightened, segmented markets effects were apparent across many markets, and intermediaries suffered from serious financing problems. In such an environment, supply changes should be expected to have a large effect on interest rates. 


\section{Evidence from QE2}

This section presents data from the QE2 event study and analyzes the channels through which QE2 operated.

\section{III.A. Event Study}

We perform an event study of QE2 similar to that of QE1. There are two relevant sets of events in QE2. First, in its August 10, 2010, statement, the FOMC announced, "The Committee will keep constant the Federal Reserve's holdings of securities at their current level by reinvesting principal payments from agency debt and agency mortgage-backed securities in longer-term Treasury securities." Before this announcement, market expectations were that the Federal Reserve would let its MBS portfolio run off, ${ }^{10}$ thereby reducing reserve balances in the system and allowing the Fed to exit from its nontraditional monetary policies. Thus, the announcement of the Federal Reserve's intent to continue QE revised market expectations. Moreover, the announcement indicated that QE would shift toward longer-term Treasuries, and not agencies or agency MBSs as in QE1. As a back-of-the-envelope computation, suppose that the prepayment rate for the next year on $\$ 1.1$ trillion of MBSs was 20 percent. ${ }^{11}$ Based on this, the announcement indicated that the Federal Reserve intended to purchase $\$ 220$ billion [ $\$ 1.1$ trillion $\times 0.2$ ] of Treasuries over the next year, $\$ 176$ billion $[\$ 1.1$ trillion $\times(1-0.2) \times 0.2]$ over the subsequent year, and so on. It is unclear from the announcement how long the Federal Reserve expected to keep the reinvestment strategy in place.

The September 21, 2010, FOMC announcement reiterates this message: "The Committee also will maintain its existing policy of reinvesting principal payments from its securities holdings."

The second type of information for QE2 pertains to the Federal Reserve's intent to expand its purchases of long-term Treasury securities. The fourth paragraph of the September 21 FOMC statement says, "The Committee will continue to monitor the economic outlook and financial developments and is prepared to provide additional accommodation if needed to support the economic recovery" (emphasis added).

10. See Federal Reserve Board Chairman Ben Bernanke's Monetary Policy Report to Congress on July 21, 2010, discussing the "normalization" of monetary policy. The issue is also highlighted in Bernanke's testimony on March 25, 2010, on the Federal Reserve's exit strategy.

11. The Federal Reserve's holdings of MBSs were $\$ 1,118$ billion on August 4,2010 , and $\$ 897$ billion on August 3, 2011 (according to the H4 report of the Federal Reserve), for an annualized decline of 19.7 percent. 
This paragraph includes new language relative to the corresponding paragraph in the August 10, 2010, FOMC statement, which read, "The Committee will continue to monitor the economic outlook and financial developments and will employ its policy tools as necessary to promote economic recovery and price stability." The new language in the September 21 statement follows the third paragraph of that statement in which the FOMC reiterates its intention to maintain its target for the federal funds rate and reiterates its policy of reinvesting principal payments from its securities holdings. The new language was read by many market participants as indicating new stimulus by the Federal Reserve, and particularly an expansion of its purchases of long-term Treasuries. For example, Goldman Sachs economists, in their market commentary on September 21, 2010, refer to this language and conclude that the Federal Reserve intended to purchase up to $\$ 1$ trillion of Treasuries. ${ }^{12}$

The following announcement from the November 3, 2010, FOMC statement makes such an intention explicit: "The Committee will maintain its existing policy of reinvesting principal payments from its securities holdings. In addition, the Committee intends to purchase a further $\$ 600$ billion of longer-term Treasury securities by the end of the second quarter of 2011."

The November 3 announcement was widely anticipated. A Wall Street Journal survey of private sector economists in early October 2010 found that they expected the Federal Reserve to purchase about $\$ 750$ billion in QE2. ${ }^{13}$ We have noted above the expectation, as of September 21, 2010, by Goldman Sachs economists of $\$ 1$ trillion of purchases. Based on this, one would expect the November 3 announcement to have little effect. (Estimates in the press varied widely, but the actual number of $\$ 600$ billion was within the range of numbers commonly mentioned.)

Figure 4 presents intraday data on the 10-year Treasury bond yield around the announcement times of the above FOMC statements. The August 10 announcement appears to have contained significant news for the Treasury market, reducing the yield in a manner that suggests that market expectations regarding $\mathrm{QE}$ were revised upward. The reaction to the September 21 announcement is qualitatively similar. After the November 3 announcement, Treasury yields increased but then fell somewhat. This reaction suggests that markets may have priced in more than a $\$ 600$ billion QE announcement.

12. "FOMC Rate Decision-Fed Signals Willingness to Ease Further if Growth or Inflation Continue to Disappoint," Goldman Sachs newsletter, New York, September 21, 2010.

13. Jon Hilsenrath and Jonathan Cheng, "Fed Gears Up for Stimulus," Wall Street Journal, October 26, 2010. 
Figure 4. Intraday Yields and Trading Volumes on QE2 Event Days ${ }^{a}$

\section{Yields}

Aug. 10, 2010

Percent per year

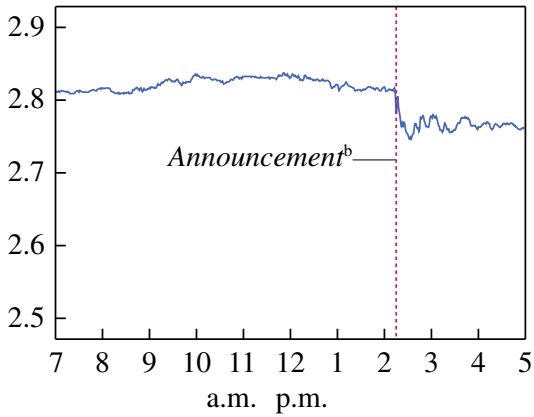

Time of day

Sep. 21,2010

Percent per year

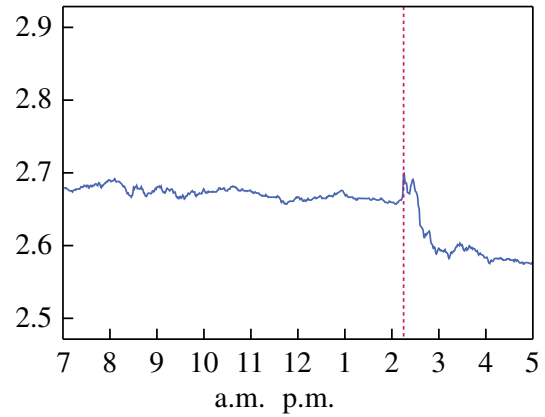

Time of day

Nov. 3, 2010

Percent per year

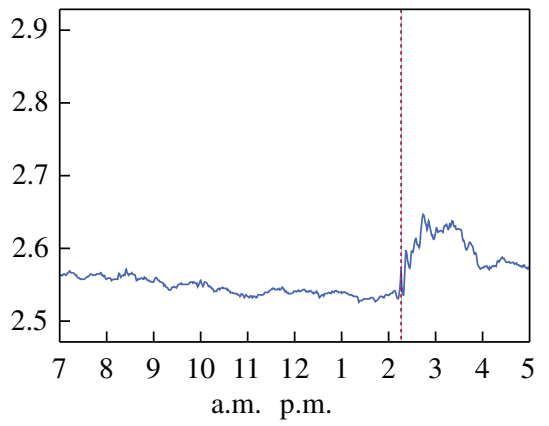

Time of day

In our event study, we aggregate across the August 10 and September 21 events, which seem clearly to be driven by upward revisions in QE expectations. We do not add in the change from the November 3 announcement, as it is unclear whether only the increase in yields after that announcement or also the subsequent decrease was due to QE2. (Furthermore, the large 2-day reaction to the November 3 announcement may not have been due to QE2, since a lot of it happened the morning of November 4, around the time new numbers were released for jobless claims and productivity.) As noted in section II.A, given our objective of understanding the channels of QE, it is important to focus on events that we can be sure are relevant to $\mathrm{QE}$. 
Figure 4. Intraday Yields and Trading Volumes on QE2 Event Days ${ }^{\mathrm{a}}$ (Continued)

Aug. 10, 2010

Million dollars of face value

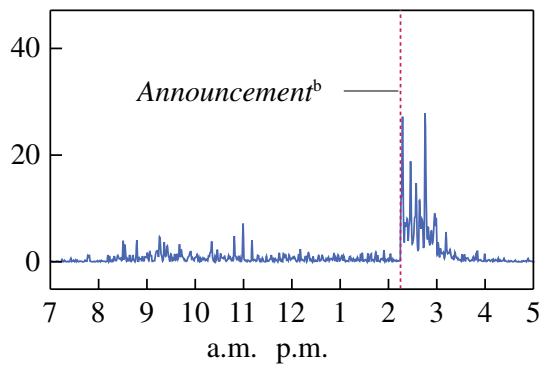

Time of day

Nov. 3, 2010

Million dollars of face value

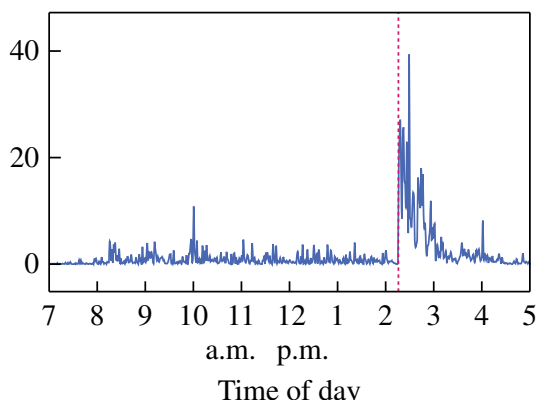

Sep. 21, 2010

Million dollars of face value

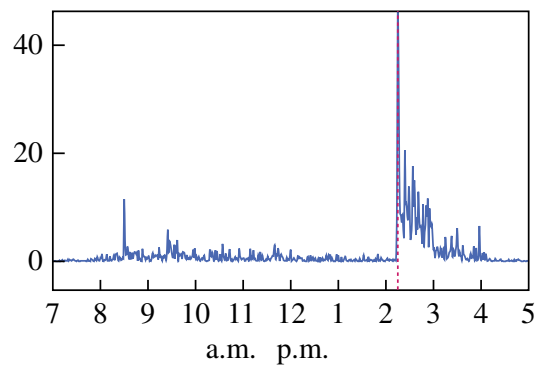

Time of day

Source: BG Cantor data.

a. Yields and trading volumes are minute-by-minute averages and total volume by minute, respectively, for the on-the-run 10-year bond on the indicated dates.

b. Minute of the appearance in Factiva of the first article covering the QE-related announcement.

Additionally, we present information for both 1-day changes and 2-day changes, but we focus on the 1-day changes in our discussion. The reason is that market liquidity had normalized by the fall of 2010, and looking at the 2-day changes would therefore likely add noise to the data.

\section{III.B. Analysis}

Table 5 provides data on the changes in Treasury, agency, and agency MBS yields over the event dates. Table 6 provides data on changes in corporate bond yields, CDS rates, and CDS-adjusted corporate yields.

The effects of QE2 on yields are consistently much smaller than the effects found for QE1. This could be partially due to omission of relevant 


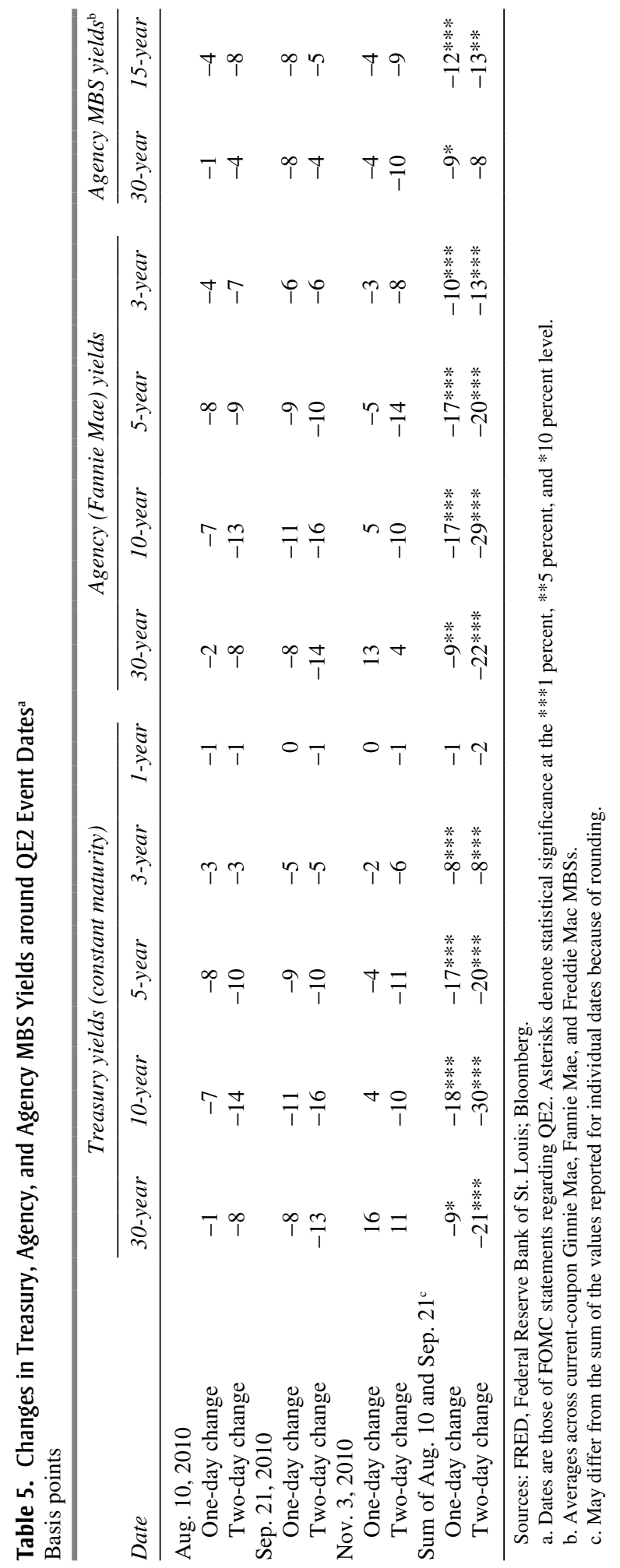




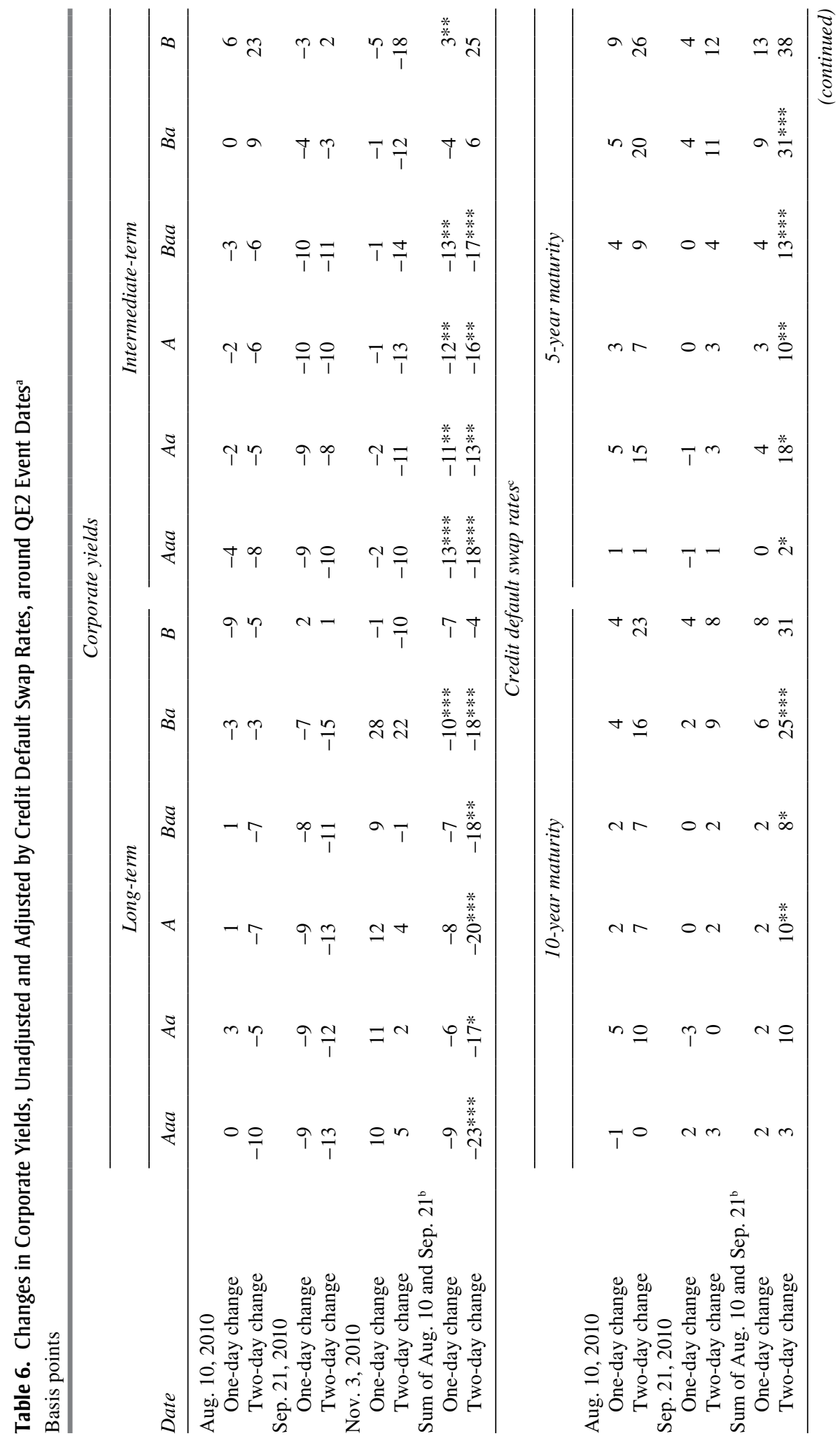




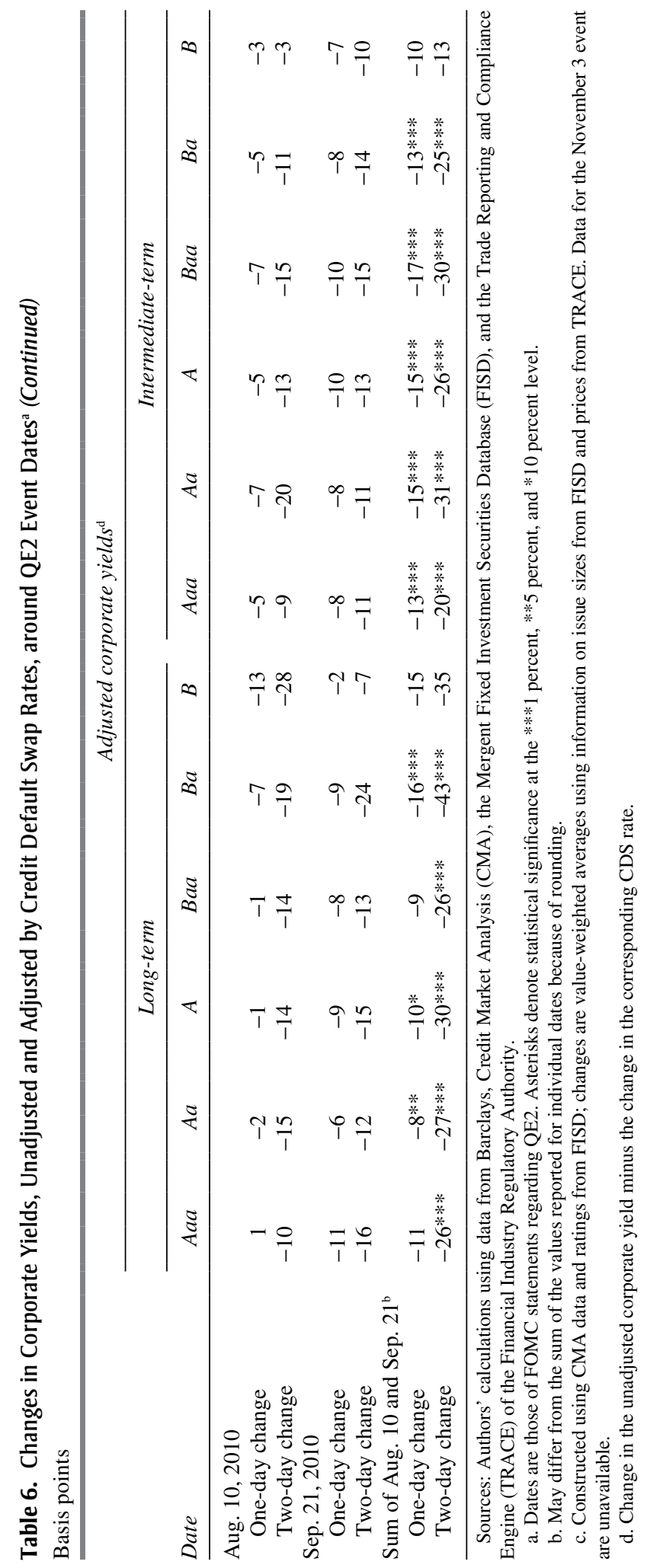


additional event dates for QE2. We considered various additional events (for example, speeches by Federal Reserve officials) but, using intraday Treasury yield data, did not find any days with dramatic Treasury yield declines right around the events. This does not mean that considering only a few QE2 event dates captures all of the impact of QE2, but only that the market may have updated its perceptions about QE2 not only on Federal Reserve announcement dates but also on dates of bad economic news. Decomposing the yield impact of, for example, a GDP announcement into its "standard effects" and its indirect effect due to its impact on the likelihood of QE is difficult, and we do not pursue it.

The fact that the effects of QE2 are fairly small makes it more difficult to discern all of the various channels involved in QE2 than in QE1. That said, we offer some conclusions regarding the channels:

- There is significant evidence of the signaling channel. The 12th-month federal funds futures contract (table 2 ) falls by $4 \mathrm{bp}$. The 24th-month contract falls by $11 \mathrm{bp}$. Extrapolating out from this 24th-month contract suggests that we can explain moves in longer-term rates of up to $11 \mathrm{bp}$ following our first approach outlined in our discussion of signaling for QE1. Turning to our second approach, we show in figure 5 the average pre- and post-QE2

Figure 5. Yield Curves Calculated from Federal Funds Futures before and after QE2 Event Days $^{\mathrm{a}}$

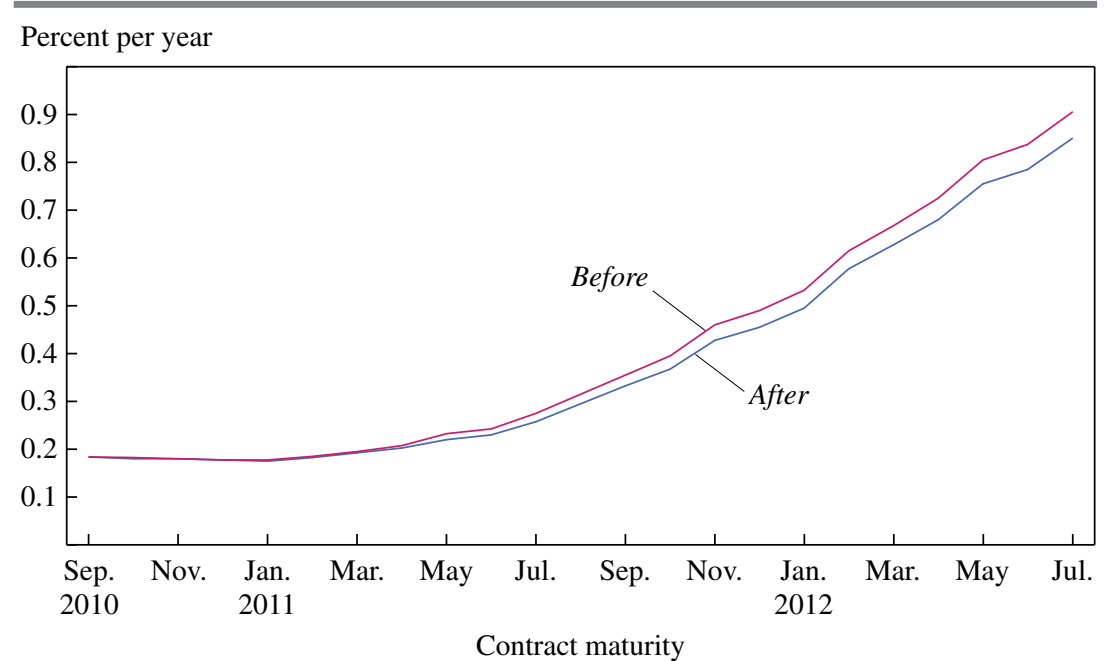

Source: Bloomberg data.

a. Yields are computed the day before each QE2 event date and again the day after. All the before-event yields are then averaged across events, and likewise for the after-event yields. 
yield curves from the federal funds futures contracts. The graph suggests a shift forward in time of the anticipated rate hike cycle. We can again estimate how large this shift is. Because the slope of the futures curve from figure 5 is not constant, the computation is sensitive to exactly which point one uses to evaluate the time shift. Using the slope and vertical shift at July 2012, we estimate that the time shift is 3.2 months, whereas using the slope and vertical shift at July 2011, we estimate it at 2.1 months. The latter implies a fall in 5-year rates of $11 \mathrm{bp}$, a fall in 10-year rates of $7 \mathrm{bp}$, and a fall in 30-year rates of $2 \mathrm{bp}$. A time shift of 3.2 months implies a fall in 5 -year rates of $16 \mathrm{bp}$, a fall in 10-year rates of $11 \mathrm{bp}$, and a fall in 30-year rates of $4 \mathrm{bp}$. The fall of $16 \mathrm{bp}$ in the 5-year rate from this computation is too large relative to the 11-bp upper bound from our first approach, suggesting that the computation at 2.1 months is more plausible.

These numbers appear to be in line with the CDS-adjusted corporate bond yield changes as well as the agency MBS yield changes. Note also that the intermediate-term corporate rates (those for bonds of about 4 years' duration) in table 6 fall more than the long-term rates (10 years' duration) and that the 15-year agency MBS yields (3 years' duration) in table 5 fall more than the 30-year yields (7 years' duration). Both moves are consistent with the signaling channel. Thus, the signaling channel can plausibly explain all of the movements in the corporate bond rates and the agency MBS yields. The only exceptions are the long-term Ba and B categories, where the CDS rates appear to rise sharply with no corresponding effects on bond yields. We are unsure of what is driving the divergence between CDS rates and bond yields for these categories.

-Given that MBS yield changes are fully accounted for by the signaling channel, there is no evidence of a prepayment risk channel for QE2. This is as would be expected given that QE2 did not involve MBS purchases. Similarly, there does not appear to be a substantial duration risk premium channel. Given that the size of the signaling channel is roughly the same as the decline in the CDS-adjusted corporate rates, there is no additional yield decline to be explained by a duration risk premium reduction.

- There is evidence for a safety channel. Yields on 10-year agency and Treasury bonds, both of which have near-zero default risk, fall more than the CDS-adjusted corporate bond yields. With a signaling effect for 10 -year bonds of between 7 and $11 \mathrm{bp}$, and a fall in 10-year Treasury and agency bond yields of 17 to $18 \mathrm{bp}$, the safety effect is between 6 and $11 \mathrm{bp}$ for the 10-year agency bonds and Treasuries.

- There does not appear to be a liquidity channel. Treasury and agency yields fall by nearly the same amounts, so that their spread, which we use 
to measure liquidity, appears unchanged. This result is plausible because liquidity premiums in bond markets were quite low in late 2010, as market liquidity conditions had normalized. Consider the following data (as of August 10, 2010):

\begin{tabular}{lcc}
\hline & \multicolumn{2}{c}{ Yield (basis points) } \\
\cline { 2 - 3 } Maturity & Treasury bill & $\begin{array}{c}\text { Tier 1 nonfinancial } \\
\text { commercial paper }\end{array}$ \\
\hline 1 week & 13 & 20 \\
1 month & 15 & 19 \\
3 months & 15 & 27 \\
\hline
\end{tabular}

The yield discount on the more liquid 1-week bill relative to the 1-month bill is only $2 \mathrm{bp}$, and the yield discount on the more liquid 3-month bill relative to 3 -month commercial paper is only $12 \mathrm{bp}$. The latter premium also reflects some credit risk and tax effects. Part of the reason why liquidity premiums are so low is that government policy had already provided a large supply of liquid assets to the private sector. The Federal Reserve had already increased bank reserves substantially. At the end of the third quarter of 2008, reserve balances totaled $\$ 222$ billion. At the end of the second quarter of 2010, reserve balances totaled $\$ 973$ billion, and the government increased the supply of Treasury bills from $\$ 1,484$ billion to $\$ 1,777$ billion over this same period. ${ }^{14}$ These arguments suggest that the effects on liquidity premiums should be negligible via the liquidity channel.

- There is no evidence for a credit risk channel as CDS rates rise, especially for lower-grade bonds. This may indicate that QE2 (unlike QE1) did not have a substantial stimulating effect on the economy. It is possible that CDS rates rose (rather than simply remained unchanged) because the market inferred from the Federal Reserve's decision to pursue QE2 that the economy was in worse shape than previously thought.

-Table 7 provides data on inflation swaps and TIPS yields for the event dates. Inflation expectations rise with QE2. The rate on the 10-year inflation swap rises by $5 \mathrm{bp}$, while that on the 30-year inflation swap rises by $11 \mathrm{bp}$. The 10 -year TIPS yield falls by $25 \mathrm{bp}$. Comparing this number with

14. Federal Reserve, Flow of Funds Accounts of the United States, table L.109 (depository institution reserves), and U.S. Treasury, Monthly Statement of the Public Debt of the United States, various issues. 


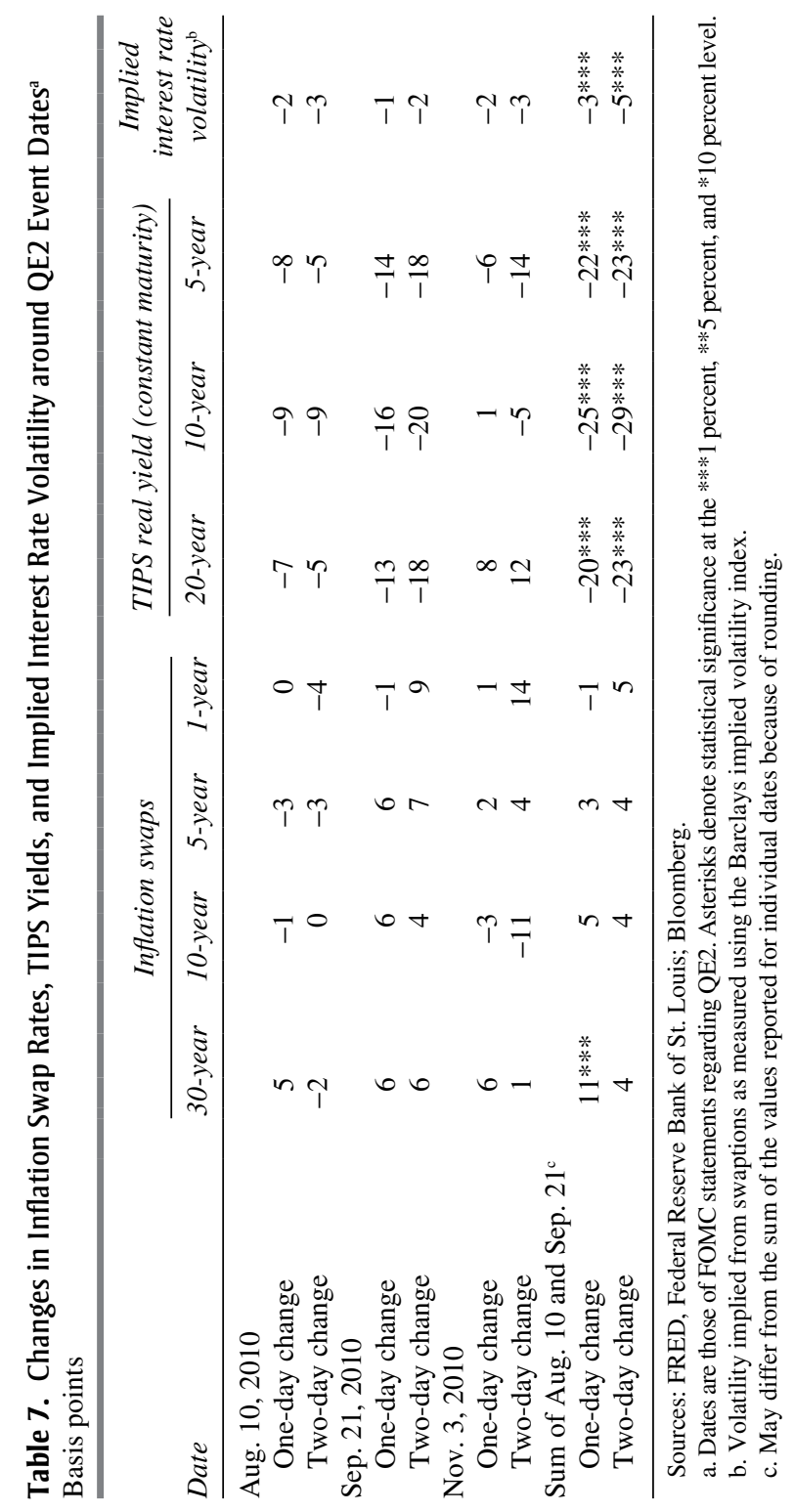


the CDS-adjusted declines in yields on long-term Aaa and Baa bonds implies that inflation expectations rise by $14 \mathrm{bp}$ or $16 \mathrm{bp}$, respectively, at the 10-year horizon. The implied volatility on swaptions falls by $3 \mathrm{bp}$, indicating a slight decrease in inflation uncertainty.

\section{III.C. Summary and Discussion}

The QE2 data suggest three primary channels for this Treasuries-only policy. The signaling channel lowered yields on 5-year bonds by 11 to $16 \mathrm{bp}$ and on 10-year bonds by 7 to $11 \mathrm{bp}$, depending on the estimation method used. The safety channel lowered yields on low-default-risk 10-year bonds by an additional 6 to $11 \mathrm{bp}$. Furthermore, there is significant evidence of an increase in inflation expectations ( 5 to $16 \mathrm{bp}$ over the 10-year horizon), suggesting that real interest rates fell for all borrowers. The main effect on the nominal rates that are most relevant for households and many corporations - mortgage rates and rates on lower-grade corporate bondswas thus through the signaling and inflation channels, rather than from a portfolio balance effect via the QE2 Treasury purchases.

Our finding that signaling played a primary role in QE2 is consistent with the market's reaction to the August 9, 2011, FOMC statement, which said that "the Committee currently anticipates that economic conditionsincluding low rates of resource utilization and a subdued outlook for inflation over the medium run-are likely to warrant exceptionally low levels for the federal funds rate at least through mid-2013." From August 8 to August 9, Treasury rates declined by 12, 20,20, and $12 \mathrm{bp}$ at maturities of $3,5,10$, and 30 years, respectively. An important question is thus whether the Federal Reserve could have achieved the signaling and inflation impact on yields seen in the Treasuries-only policy of QE2 from a commitment like that in the August 9, 2011, statement, and thus without taking on additional balance sheet risk.

It is also interesting to contrast the channels in the QE2 policy with those in the QE1 policy, and to consider the Federal Reserve's QE3 action on September 21, 2011, in this light. We find that the main channel in lowering MBS rates (and thus household mortgage rates) and corporate borrowing rates in QE1 is a portfolio balance effect via the MBS purchases during a time of market stress (and its associated effects on the housing market and the real economy). We also find a smaller, but still sizable, signaling effect in QE1. The QE2 channel for MBS and corporate borrowing rates appears to be entirely through the signaling effects. QE3 involves both purchases of long-dated Treasuries (funded by corresponding sales of shorter-maturity Treasuries) as well as investments in agency MBSs. The 
two relevant parts of the September 21, 2011, FOMC statement are the following: "The Committee intends to purchase, by the end of June 2012, $\$ 400$ billion of Treasury securities with remaining maturities of 6 years to 30 years and to sell an equal amount of Treasury securities with remaining maturities of 3 years or less," and "the Committee will now reinvest principal payments from its holdings of agency debt and agency mortgagebacked securities in agency mortgage-backed securities."

Our analysis of QE1 and QE2 suggests that the impact of QE3 on MBS and corporate borrowing rates should occur through a signaling effect and a portfolio balance effect based on the MBS purchases. The latter effect should be smaller than during QE1, because market conditions were less stressed in September 2011 than in late 2008 and early 2009, and MBS purchases were larger in QE1 than in QE3.

From September 20 to September 21, 2011, long-term interest rates decline substantially and across the board. The largest decline, $23 \mathrm{bp}$, is in the 30-year MBS (as previously, this is based on averaging the yields on current-coupon Fannie Mae, Ginnie Mae, and Freddie Mac securities); the yield on the comparable-duration 10-year Treasury declines by $7 \mathrm{bp}$, that on the 10-year agency by $2 \mathrm{bp}$, and long-term corporate rates from the Aaa to the Baa category by between 15 and $17 \mathrm{bp}$. These moves are plausibly affected by an MBS risk premium channel, with attendant effects for corporate borrowing rates, as in QE1. On the other hand, the market responses differ in three other ways from those following QE1. First, the federal funds futures contract barely moves (the 24th-month contract falls by $1 \mathrm{bp}$ ), suggesting a negligible signaling channel. It is possible that the August 9, 2011, statement reduced the amount of room remaining for rate reductions via the signaling channel. Second, default risk rises, with 10 -year investment-grade CDS rates rising by 9 bp and high-yield CDS rates rising by 1 bp. (We do not have firm-level CDS data for the QE3 period. The CDS numbers reported are based on data from Markit obtained via Datastream.) The rise in perceived default risk despite an observed decrease in corporate bond yields is unlike what happened in QE1 and is puzzling to us. One possible answer is that other news affecting financial markets that day also moved asset prices. When we look at intraday asset price changes, we find that Treasury and MBS rates decline sharply within minutes after the announcement. That same day the S\&P 500 index declines by around 3 percent, but the bulk of this decline occurs a full hour after the FOMC announcement. Thus, it is possible that bad news affected the market later in the day, driving up CDS rates and driving down all yields. We do not have intraday data on corporate bond yields and CDS rates with which 
to evaluate this hypothesis. Finally, unlike in both QE1 and QE2, inflation expectations measured from inflation swaps are down $8 \mathrm{bp}$ at the 30 -year horizon and $4 \mathrm{bp}$ at the 10-year horizon. It is possible that since QE3 involved no change in the monetary base, markets perceived the operation not to be inflationary. Moreover, both the increased default risk and the decrease in inflation expectations could be driven by the markets updating their odds of a slowdown in economic growth. ${ }^{15}$

\section{Regression Analysis of the Safety Channel}

The event-study evidence is useful in identifying channels for QE. Although it provides guidance on the magnitudes of the effects through $\mathrm{QE}$, it is hard to interpret the numbers precisely, because event-study measures are dependent on the dynamics of expectations through the event. That is, the asset market reaction depends on the change in the expectation of QE over the event. We have no direct way of precisely measuring such a change, nor can we determine whether the event study is likely to over- or understate the effects of QE. In addition, the QE1 event occurred in highly unusual market conditions, so that it is hard to extrapolate numbers from that period to more normal conditions. As such, it is valuable to find alternative approaches to estimating the impact of QE. In this section we use regression analysis to provide such estimates, focusing on the long-term safety channel.

15. Another interesting case study for QE is that of the United Kingdom in 2009-10, examined by Joyce and others (2010). Like QE2 in the United States, QE in the United Kingdom during this period consisted of purchases of long-term government bonds, totaling $£ 200$ billion in the U.K. case. Joyce and others (2010) document that QE led to large reductions in government bond yields, smaller effects on investment-grade bonds, and more erratic effects on non-investment-grade corporate bonds. They find quite small effects on derivatives measures of future policy rates (to capture the signaling effects). The authors do not consider the effects on MBS rates, CDS rates, or expected inflation. It would be interesting to revisit the U.K. QE evidence explicitly in the framework of our channels approach. Regarding our long-term safety channel, a few observations from the U.K. experience are striking. Joyce and others (2010, chart 7) find that on the first QE event date, yields on gilts (government bonds) moved dramatically out to a maturity of 15 years, with sharply smaller effects on yields just longer than the 15-year maturity, suggesting that the market did not expect bonds beyond that maturity to be purchased. On the second QE event date, the Bank of England announced that the maturities purchased would be 5 to 25 years. On that date, yields on bonds from 15 to 25 years' maturity declined sharply more than yields on bonds between 5 and 15 years, and yields on bonds just above 5 years declined much more than yields on bonds just below 5 years. This suggests the presence of investors with preferredhabitat demand for very safe bonds of particular maturities, and the absence of sufficient arbitrage activity from other investors to smooth out the impact of announced gilt purchases across the yield curve. 


\section{IV.A. Regressions}

We build on the regression analysis in Krishnamurthy and VissingJorgensen (2010) to estimate the effect of a purchase of long-term securities via the safety channel. We focus on the safety channel because it appears from the event studies to be a dominant effect, and because long time series of historical data exist that allow us to elaborate on this channel.

The regression approach we have taken in prior work can be explained through figure 1. Consider the yield (or price) difference between a lowdefault-risk bond, such as a Treasury bond, and a Baa-rated bond. This yield difference includes both a default risk premium due to standard risk considerations and a safety premium due to clientele demands for particularly safe assets. We disentangle the default risk and the safety premium by observing that the safety premium is decreasing in the supply of safe assets, including Treasuries, whereas the default risk component can be controlled for using empirical default measures. The empirical approach is to regress the Baa-Treasury spread on the supply of Treasuries as well as on standard measures of default.

As we explain in Krishnamurthy and Vissing-Jorgensen (2010), the BaaTreasury spread reflects both a liquidity premium, since Treasuries are much more liquid than corporate bonds, and a safety premium. The Baa-Treasury spread is thus likely to overstate the safety premium. ${ }^{16} \mathrm{We}$ therefore also consider the spread between Baa- and Aaa-rated corporate bonds (as we did for $\mathrm{QE}$ ). The coefficient from the Baa-Aaa regression is a pure read on the safety premium, because Baa and Aaa corporate bonds are equally illiquid. However, it is an underestimate of the safety effect as may be reflected in Treasuries or agencies, because although Aaa corporate bonds are safe, they still contain more default risk than Treasuries or agencies. For example, Moody's reports that over 10 years, the historical average default probability of a corporate bond that is rated Aaa today is 1 percent (whereas it is likely close to zero for Treasuries and around 8 percent for Baa bonds). We note that an alternative spread to capture the price of long-term safety would be that between Treasury yields and duration-matched federal funds futures (following our approach to estimating the safety channel for QE, with the exception that agency yields could not be used historically because

16. Note that, as discussed above, in QE the liquidity effect of changes in Treasury supply works to increase Treasury yields relative to yields on less liquid assets, because the QE Treasury purchases were financed by reserves and thus represented an increase in the supply of liquidity. In general, however, a reduction in the supply of Treasuries available to investors will not be associated with a change in reserves and will thus reduce the supply of liquidity and reduce Treasury yields relative to yields on less liquid assets such as corporate bonds. 
of their higher risk before the government takeover). However, data on federal funds futures contracts are not available far enough back in time to allow meaningful regressions in annual data.

In Krishnamurthy and Vissing-Jorgensen (2010), we mainly focus on the effect of changes in the total supply of Treasuries, irrespective of maturity, on bond yields. For evaluating QE, we are interested more in asking how a change in the supply of long-term Treasuries (and agency bonds) will affect yields. Accordingly, we construct a maturity-based measure of debt supply as follows. For each Treasury issue in the Center for Research in Security Prices' Monthly U.S. Treasury Database, we compute the market value of that issue multiplied by the duration of the issue divided by $10 .{ }^{17}$ We normalize by 10 to express the supply variable in " 10 -year equivalents." We then sum these values across Treasury issues with remaining maturity of 2 years or more. We denote the sum as LONG-SUPPLY. We also construct the (unweighted) market value across all Treasury issues (TOTAL-SUPPLY), including those with a remaining maturity of less than 2 years.

We then regress the spread between the Moody's Baa corporate bond yield and the long-term Treasury yield (Baa-Treasury), or between Moody's Baa and Aaa corporate bond yields, on $\ln$ (LONG-SUPPLY/ GDP) instrumented by TOTAL-SUPPLY/GDP and squares and cubes of TOTAL-SUPPLY/GDP. The regression includes as default controls stock market volatility (the standard deviation of weekly stock returns over the preceding year) and the slope of the yield curve (the 10-year Treasury yield minus the 3-month yield). Data sources are as described in detail in Krishnamurthy and Vissing-Jorgensen (2010). The regressions are estimated via two-stage least squares, with standard errors adjusted for an AR(1) correlation structure. It is important to instrument for LONGSUPPLY because the maturity structure of government debt is chosen by the government in a way that could be correlated with spreads. TOTALSUPPLY is strongly related to LONG-SUPPLY and is plausibly exogenous to the safety premium. (See Krishnamurthy and Vissing-Jorgensen 2010 for further details of the estimation method.) The regressions are estimated using annual data from 1949 to 2008 . The regression is

$$
\operatorname{spread}_{t}=\text { default controls }_{t}+\beta \ln \left(\text { LONG-SUPPLY }_{t} / \text { GDP }_{t}\right)+\varepsilon_{t},
$$

17. We use monthly data on prices and bond yields from the CRSP Monthly U.S. Treasury Database to empirically construct the derivative of price with respect to yield (see the online data appendix). The derivative is then used to compute the duration. 
instrumented by TOTAL-SUPPLY/GDP and squares and cubes of TOTAL-SUPPLY/GDP. The term $\beta \ln ($ LONG-SUPPLY/GDP) is the premium of interest in this regression. We evaluate the effect of a $\mathrm{QE}$ by evaluating this premium term at the pre-QE and post-QE values of LONG-SUPPLY.

The resulting $\beta$ coefficient is -0.83 ( $t$ statistic $=-5.83$ ) for the Baa-Treasury spread. For the Baa-Aaa spread, the coefficient is -0.32 $(t$ statistic $=-3.02)$.

\section{IV.B. Estimates for QE1}

Gagnon and others (2010) report that, in 10-year equivalents, the Federal Reserve had purchased $\$ 169$ billion of Treasuries, $\$ 59$ billion of agency debt, and $\$ 573$ billion of agency MBSs by February 1, 2010. The Treasury purchases were complete at $\$ 300$ billion, whereas $\$ 164$ billion of up to $\$ 200$ billion of agency securities had been purchased. We scale up the agency number to $\$ 59$ billion $\times(200 / 164)=\$ 72$ billion of 10 -year equivalents.

Agency debt and Treasury debt are almost equally safe during the QE period, whereas agency MBSs carry prepayment risk. Thus, if we consider only the Treasuries and agencies purchased and ask what effect this will have on the Baa-Aaa spread using the regression coefficient of -0.32 , we find that the effect is $4 \mathrm{bp}$ (we also use the fact that at the end of 2008, before the QE purchases, LONG-SUPPLY equaled \$1,983 billion and GDP for 2008 was $\$ 14,291.5$ billion). As we have noted, this is smaller than the true safety effect, because Aaa corporate bonds are not as safe as either agencies or Treasuries. As an upper bound, even if we use the BaaTreasury coefficient (which includes a liquidity premium), the estimate is $11 \mathrm{bp}$. Although the event study may not identify the precise economic impact of QE via the long-term safety channel, for reasons discussed earlier, our regression estimates still appear quite small. This suggests that had QE1 taken place at an "average" demand for safety (as estimated by our regressions), its effects via the safety channel would have been much smaller than what we observed.

\section{IV.C. Estimates for QE2}

In QE2 the Federal Reserve announced that it would purchase $\$ 600$ billion of Treasuries and roll over the maturing MBSs in its portfolio into long-term Treasuries. We suggested earlier that the latter translates to a purchase of $\$ 220$ billion over the next year, and $\$ 176$ billion for the following year, if the policy was kept in place. For the sake of argument, let us 
suppose that the market expects the policy to be in place for only one year; then the total effect is to purchase $\$ 820$ billion of Treasuries.

An $\$ 820$ billion Treasury purchase can have a large effect on safety premiums. Moreover, QE2 occurred during more normalized market conditions, so that estimates based on the -0.32 coefficient are likely to be appropriate during this period. The $\$ 820$ billion of Treasuries translates to $\$ 511$ billion of 10-year equivalents, based on the planned maturity breakdown provided by the Federal Reserve Bank of New York. ${ }^{18}$ Based on these numbers, and using the -0.32 coefficient, we find that QE2 should have increased the safety premium by $8 \mathrm{bp}$. Using the upper-bound coefficient of -0.83 , we estimate an effect of $20 \mathrm{bp}$. These numbers are roughly comparable to the magnitude of the safety channel for QE2 we estimated using the event-study approach.

\section{Conclusion}

We have documented that the Federal Reserve's purchases of long-term Treasuries and other long-term bonds (QE1 in 2008-09 and QE2 in 2010-11) significantly lowered nominal interest rates on Treasuries, agencies, corporate bonds, and MBSs, but with magnitudes that differed across bond types, across maturities, and across QE1 and QE2. There are several primary channels for these effects. Three of these were operative in both QE1 and QE2, and the other three only in QE1. For both QE1 and QE2 we find significant evidence for, first, a signaling channel that drives down the yield on all bonds (with larger effects on intermediate- than on longterm bonds); second, a long-term safety channel through which yields on medium- and long-maturity safe bonds fall because a unique clientele exists for extremely safe nominal assets, and Federal Reserve purchases reduce the supply of such assets and hence increase the equilibrium safety premium; and third, an inflation channel, with evidence from both inflation swap rates and TIPS showing that expected inflation increased, implying larger reductions in real than in nominal rates. The three additional channels for QE1 are, first, an MBS risk premium channel that lowers yields on MBSs (QE affected MBS yields by more than the signaling effect for QE1 but not for QE2, indicating that another main channel for $\mathrm{QE}$ is to affect the equilibrium price of mortgage-specific risk if $\mathrm{QE}$ involves purchases of MBSs); second, a default risk or default risk premium channel that lowers

18. Federal Reserve Bank of New York, "FAQs: Purchases of Longer-Term Treasury Securities" (www.newyorkfed.org/markets/opolicy/operating_policy_101103.html). 
yields on corporate bonds; and third, a liquidity channel through which QE financed by reserves increases yields on the most liquid bonds relative to less liquid bonds of similar duration. We find no evidence for an impact of $\mathrm{QE}$ on the duration risk premium.

Our results have three main policy implications. First, it is inappropriate for central banks to focus only on Treasury rates as a policy target, because changes in Treasury rates are driven by safety effects that do not carry over to mortgage and lower-grade corporate borrowing rates. Second, the beneficial effects of QE for mortgage and lower-grade corporate rates of the Federal Reserve's asset purchases are highest when these purchases involve non-Treasury assets such as MBSs. Last, a Treasuries-only policy such as QE2 has effects primarily through a signaling channel, whereby the market lowers its anticipation of future federal funds rates. An important question is thus whether the Federal Reserve could have achieved the signaling impact via a direct commitment as in the August 9, 2011, FOMC statement, and thus without taking on additional balance sheet risk.

The principal contribution of our work relative to other research on QE in the United States (D'Amico and King 2010, Gagnon and others 2010, and Hamilton and $\mathrm{Wu} 2010$ ) is that by analyzing the differential impact of $\mathrm{QE}$ on a host of interest rates and derivatives, we shed light on the channels through which $\mathrm{QE}$ affects interest rates. Although the prior literature does not discuss the channels for $\mathrm{QE}$ in as much detail as we do, it points to the operation of QE through two potential channels: the signaling channel as well as a "portfolio balance channel." Brian Sack, executive vice president of the Federal Reserve Bank of New York's Markets Group, which oversees open market operations, describes the portfolio balance channel as follows:

By purchasing a particular asset, the Fed reduces the amount of the security that the private sector holds, displacing some investors and reducing the holdings of others. In order for investors to be willing to make those adjustments, the expected return on the security has to fall. Put differently, the purchases bid up the price of the asset and hence lower its yield. These effects would be expected to spill over into other assets that are similar in nature, to the extent that investors are willing to substitute between the assets. These patterns describe what researchers often refer to as the portfolio balance channel. (Sack 2009, emphasis added)

In thinking about the portfolio balance channel, it is key to understand which assets are substitutes for those that the Federal Reserve is purchasing. Compared with prior work, we have fleshed out the portfolio balance channel in more detail. We have considered specific finance theory-based versions of the portfolio balance channel, each of which indicates how certain assets 
may substitute for others in terms of their duration risk, prepayment risk, default risk, degree of extreme safety, and liquidity. One portfolio balance channel that emerges as substantial for both QE1 and QE2 works partially through a safety channel affecting extremely safe long- and medium-term bonds. Investors have a unique demand for low-default-risk assets of particular maturities. When the Federal Reserve purchases a large quantity of such assets, investors bid up the price on the remaining low-default-risk assets, decreasing their yields. The safety channel highlights the substitutability of assets within a (low) default-risk class. In other words, the safety channel can be thought of as a preferred habitat for particular maturities, but applying only to low-default-risk assets. This channel differs from the duration risk channel. Under the duration risk channel, in which the key dimension of substitutability is duration risk, QE has an effect on long-term rates by reducing the duration risk held by investors, and thereby reducing the term premium on longer-term assets. When the Federal Reserve removes duration from the portfolios of investors, they substitute by purchasing other long-duration assets to make up for the lost duration. Longerduration assets, which substitute better for the removed duration than do short-duration assets, fall the most in yield. We do not find support for the operation of the duration risk channel. Instead, the role of duration appears to be through a preferred-habitat demand for particular maturities.

ACKNOWLEDG MENTS We thank Jack Bao, Olivier Blanchard, Greg Duffee, Charlie Evans, Ester Faia, Simon Gilchrist, Robin Greenwood, Thomas Philippon, Monika Piazzesi, Tsutomu Watanabe, the editors, and participants at seminars and conferences at Brookings, the Federal Reserve Bank of Chicago, the Board of Governors of the Federal Reserve System, the European Central Bank, the Federal Reserve Bank of San Francisco, Princeton University, Northwestern University, the Centro de Estudios Monetarios y Financieros (Madrid), the University of Pennsylvania (Wharton), the Society for Economic Dynamics, the National Bureau of Economic Research Summer Institute, the Napa Conference on Financial Markets Research, the European Finance Association, the University of Miami, the Bank of England, Stanford University, and the University of California, Berkeley, for their suggestions. We thank Kevin Crotty and Juan Mendez for research assistance. The authors declare no relevant conflicts of interest. 


\section{References}

Bernanke, Ben S. 2010. "Semiannual Monetary Policy Report to the Congress." Testimony before the Committee on Housing, Banking, and Urban Affairs, U.S. Senate, Washington (July 21).

Bernanke, Ben S., Vincent R. Reinhart, and Brian P. Sack. 2004. "Monetary Policy Alternatives at the Zero Bound: An Empirical Assessment." BPEA, no. 2: 1-78.

Clouse, James, Dale Henderson, Athanasios Orphanides, David Small, and Peter Tinsley. 2000. "Monetary Policy When the Nominal Short-Term Interest Rate Is Zero." Topics in Macroeconomics 3, no. 1, article 12.

D'Amico, Stefania, and Thomas B. King. 2010. "Flow and Stock Effects of LargeScale Treasury Purchases.” Finance and Economics Discussion Series no. 2010-52. Washington: Board of Governors of the Federal Reserve System (September).

Dudley, William C. 2010. "The Outlook, Policy Choices and Our Mandate." Remarks at the Society of American Business Editors and Writers Fall Conference, City University of New York.

Eggertsson, Gauti, and Michael Woodford. 2003. "The Zero Bound on Interest Rates and Optimal Monetary Policy." BPEA, no. 1: 139-233.

Fleckenstein, Matthias, Francis A. Longstaff, and Hanno Lustig. 2010. "Why Does the Treasury Issue TIPS? The TIPS-Treasury Bond Puzzle." Working paper. University of California, Los Angeles.

Fuster, Andreas, and Paul S. Willen. 2010. “\$1.25 Trillion Is Still Real Money: Some Facts about the Effects of the Federal Reserve's Mortgage Market Investments." Working paper. Federal Reserve Bank of Boston.

Gabaix, Xavier, Arvind Krishnamurthy, and Olivier Vigneron. 2007. "Limits of Arbitrage: Theory and Evidence from the Mortgage-Backed Securities Market." Journal of Finance 62, no. 2: 557-95.

Gagnon, Joseph, Matthew Raskin, Julie Remache, and Brian Sack. 2010. "LargeScale Asset Purchases by the Federal Reserve: Did They Work?" Staff Report no. 441. Federal Reserve Bank of New York (March).

Greenwood, Robin, and Dimitri Vayanos. 2010. "Bond Supply and Excess Bond Return.” Working paper. London School of Economics.

Hamilton, James D., and Jing Wu. 2010. "The Effectiveness of Alternative Monetary Policy Tools in a Zero Lower Bound Environment." Working paper. University of California, San Diego.

He, Zhiguo, and Arvind Krishnamurthy. 2010. "Intermediary Asset Pricing." Working paper. Northwestern University.

Joyce, Michael, Ana Lasaosa, Ibrahim Stevens, and Matthew Tong. 2010. "The Financial Market Impact of Quantitative Easing.” Working Paper no. 393. London: Bank of England.

Krishnamurthy, Arvind, and Annette Vissing-Jorgensen. 2010. "The Aggregate Demand for Treasury Debt." Working paper. Northwestern University.

Longstaff, Francis A., Sanjay Mithal, and Eric Neis. 2005. "Corporate Yields Spreads: Default Risk or Liquidity? New Evidence from the Credit-Default Swap Market." Journal of Finance 60, no. 5: 2213-54. 
Piazzesi, Monika, and Eric T. Swanson. 2008. "Futures Prices as Risk-Adjusted Forecasts of Monetary Policy." Journal of Monetary Economics 55, no. 4: 677-91.

Sack, Brian. 2009. "The Fed's Expanded Balance Sheet." Remarks at the Money Marketeers of New York University, New York (December 9). www.newyorkfed.org/newsevents/speeches/2009/sac091202.html.

Swanson, Eric. 2011. "Let's Twist Again: A High-Frequency Event-Study Analysis of Operation Twist and Its Implications for QE2.” BPEA (Spring): 151-88.

Vayanos, Dimitri, and Jean-Luc Vila. 2009. "A Preferred Habitat Model of the Term Structure of Interest Rates.” Working paper. Financial Markets Group, London School of Economics.

Wright, Jonathan. 2011. "What Does Monetary Policy Do to Long-Term Interest Rates at the Zero Lower Bound?" Working paper. Johns Hopkins University. 


\section{Comments and Discussion}

\section{COMMENT BY}

SIMON GILCHRIST Overall this is an excellent paper. Arvind Krishnamurthy and Annette Vissing-Jorgensen consider the economic effect of large-scale asset purchases (LSAPs) by the Federal Reserve for a rich variety of fixed-income assets. They do so by extending previous research in this area to consider the announcement effect of LSAP programs on changes in yields on a broad array of securities. The organizing principle of the paper is that the effects of LSAP announcements can be decomposed into the various channels emphasized in the asset pricing literature, such as the duration, liquidity, safe haven, and default risk channels, while also accounting for the effect that such announcements may have on expectations of both inflation and the course of monetary policy.

The paper is carefully written and the analyses are well executed. The principal findings are persuasive, namely, that LSAP announcements primarily work through a combination of forces that include monetary announcement effects, increased inflation expectations, reductions in overall credit risk, and an effect that works through the safe haven channel (what the authors call the "safety channel") emphasized in the authors" previous research. The paper also includes a useful analysis of intraday movements in Treasury yields and volumes during announcement days, providing readers with greater confidence that the event-study methodology commonly employed in this literature is sound.

The paper emphasizes that the QE1 announcements worked in part because they included mortgage-backed securities and, by reducing the risk premiums associated with prepayment risk, likely benefited the financial intermediaries holding such assets and increased the overall willingness to lend in the mortgage market. More generally, according to the intermediary asset pricing theories emphasized by Tobias Adrian, Emanuel Moench, 
and Hyun Song Shin (2010) and by Zhiguo He and Krishnamurthy (2010), to the extent that LSAPs work through intermediary balance sheets, they may influence the prices of a variety of assets in which such intermediaries specialize. These include securities related to mortgage lending activity and possibly fixed-income securities of the nonfinancial sector.

This suggests that a potentially important channel through which LSAPs influence economic activity is their effect on the aggregate balance sheet of the financial intermediary sector. To the extent that LSAPs improve financial intermediary balance sheets, one would expect LSAP announcements to have a significant impact on CDS rates of financial intermediaries (that is, spreads on credit default swaps on securities issued by those intermediaries). In my comments below, I therefore focus on this issue. Following the authors' overall methodology, I consider the effect of LSAP announcements on the CDS rates of large financial holding companies. Along the way, I propose a few adjustments to the methodology used in this literature, stemming from current research by myself and Egon Zakrajšek (Gilchrist and Zakrajšek 2011) that was in part prompted by my opportunity to discuss this paper. In particular, I examine the residual effect of changes in asset prices on Treasury rates, after controlling for the relationship prevailing on nonannouncement days. I argue that such a procedure provides an alternative way of understanding the economic forces at work through LSAPs. I also propose an instrumental variables procedure to quantify the effect of LSAPs on asset prices. This procedure estimates the effect of a movement in Treasury yields engineered by LSAP announcements on the yields of alternative assets such as CDSs. To the extent that some QE announcements have more of an impact on Treasury yields than others, this methodology provides an overall metric for assessing the extent to which movements in Treasury yields can influence alternative asset classes via the announcement mechanism.

To analyze the effect of LSAP announcements on the CDS rates of financial intermediaries, I concentrate on the rates of 5-year CDSs for the top five U.S. financial holding companies: Bank of America, Citigroup, Goldman Sachs, JP Morgan Chase, and Morgan Stanley. The data are the same as those used in Gilchrist and Zakrajšek (2011) and come from Markit. The sample covers the 925 trading days from January 2008 through October 2011.

Figure 1 plots the median 5-year CDS rate for the above five companies and the median rate for a group of other large bank holding companies. The figure shows that the perceived default risk of financial intermediaries started to rise before the onset of the recession in late 
Figure 1. CDS Rates for Large Bank Holding Companies, January 2002-June 28, 2011ª

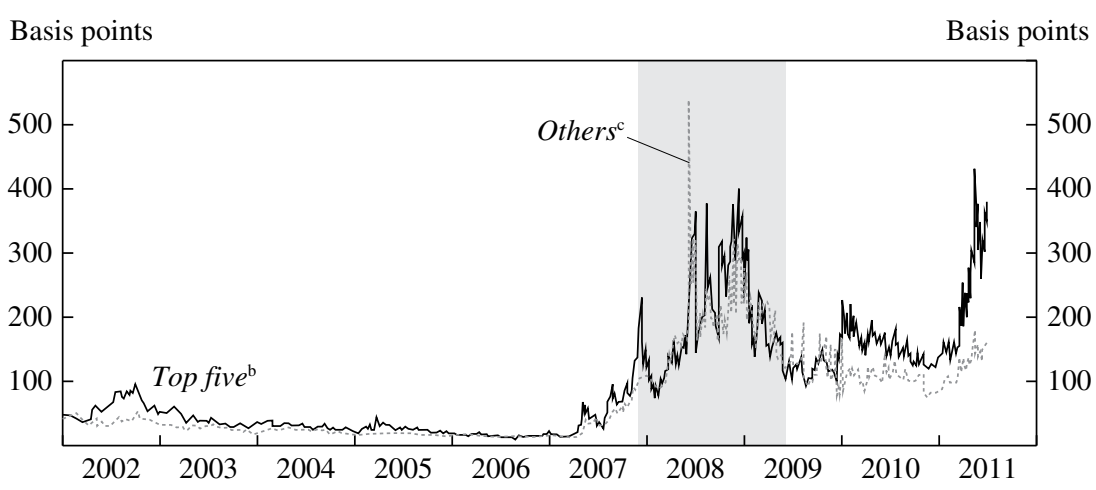

Source: Markit.

a. Daily observations of the median spread on 5-year CDSs on debt securities issued by the companies in the indicated group. Shading indicates recession.

b. Bank of America, Citigroup, Goldman Sachs, JP Morgan Chase, and Morgan Stanley.

c. BB\&T, Fifth Third, Keycorp, M\&I, Mellon Financial, Northern Trust, PNC, National City, Suntrust, USB, Wachovia, Wells Fargo, and Comerica.

2007. This rise coincides with the initial decline in housing prices that occurred that year. CDS rates peaked during the financial turmoil of late 2008 and subsided somewhat thereafter. Owing to the exposure of large financial holding companies to sovereign risk in Europe, their perceived default risk has now risen to levels comparable to those seen during the depth of the financial crisis.

Figure 2 provides a snapshot of movements in CDS rates in a 20-day window around the LSAP announcement dates identified by the authors as associated with QE1. The data are normalized to zero on the day before the announcement date and thus plot deviations from this point for each of the five dates, along with the average deviation that occurs over the window. The top and bottom panels show the median change in 5-year CDS rates for the five largest bank holding companies and for the other bank holding companies, respectively. On average, there is no noticeable effect on CDS rates for either group around announcement days. Furthermore, with the exception of the December 16 announcement, CDS rates tend to either rise or show no response. CDS rates for the top five financial holding companies do fall substantially in the 2-day window following the December 16 announcement. This date is unusual, however, because that announcement also led to an increase in Treasury yields rather than a decrease. 
Figure 2. Changes in CDS Rates for Bank Holding Companies around QE1 Announcement Days ${ }^{\mathrm{a}}$

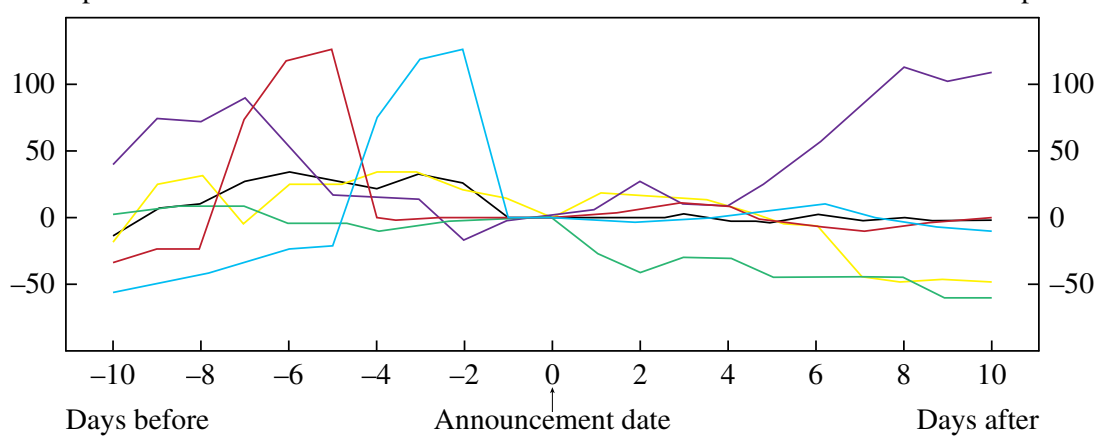

Basis points

Others

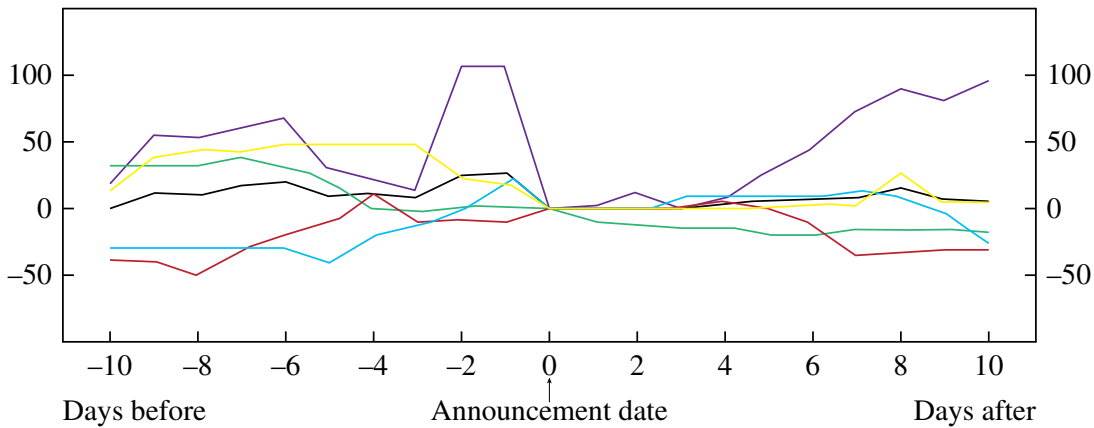

Nov. 25, 2008 Dec. 16, $2008-$ Mar. 18, 2009
Dec. 1, 2008 - Jan. 28, 2009 - Average

Source: Markit.

a. Announcement dates are those identified in Krishnamurthy and Vissing-Jorgensen, this volume. The series for each date plots the median daily change in the spreads on 5-year CDSs on debt issued by the companies in the indicated group. "Average" is the simple average of these medians on the indicated date. The "top five" bank holding companies and "others" are those listed in figure 1.

I now consider these results more formally by using regression analysis to study the effect of LSAP announcements on default risk for the five largest financial holding companies. Following the analysis of Krishnamurthy and Vissing-Jorgensen, I begin by considering the effect of both the current and the 1-day-lagged LSAP announcements on the 1-day change in the 5-year CDS rate of these five financial holding companies. I aggregate 
Table 1. Regressions Estimating the Effect of LSAP Announcements on 5-Year CDS Rates of Large Financial Holding Companies ${ }^{\mathrm{a}}$

\begin{tabular}{lccccc}
\hline & \multicolumn{5}{c}{ Company } \\
\cline { 2 - 6 } & & & & JP \\
& Bank of & & Goldman & Morgan & Morgan \\
Announcement & America & Citigroup & Sachs & Chase & Stanley \\
\hline QE1, current effect & -0.02 & 0.00 & -0.02 & -0.02 & -0.07 \\
& $(0.05)$ & $(0.08)$ & $(0.08)$ & $(0.03)$ & $(0.19)$ \\
QE1, 1-day-lagged effect & -0.01 & -0.02 & -0.01 & -0.03 & -0.00 \\
& $(0.05)$ & $(0.08)$ & $(0.08)$ & $(0.03)$ & $(0.19)$ \\
QE2, current effect & 0.03 & 0.02 & 0.04 & 0.03 & 0.00 \\
& $(0.07)$ & $(0.13)$ & $(0.13)$ & $(0.05)$ & $(0.30)$ \\
QE2, 1-day-lagged effect & 0.07 & 0.12 & 0.09 & 0.07 & 0.08 \\
& $(0.07)$ & $(0.13)$ & $(0.13)$ & $(0.05)$ & $(0.30)$ \\
QE3, current effect & 0.42 & 0.32 & 0.30 & 0.15 & 0.84 \\
& $(0.11)$ & $(0.18)$ & $(0.18)$ & $(0.07)$ & $(0.42)$ \\
QE3, 1-day-lagged effect & 0.28 & 0.18 & 0.22 & 0.13 & 0.51 \\
& $(0.11)$ & $(0.18)$ & $(0.18)$ & $(0.07)$ & $(0.42)$ \\
$R^{2}$ (no. of observations & 0.02 & 0.00 & 0.00 & 0.01 & 0.00 \\
= 925) & & & & & \\
Probability that the sum & & & & & \\
of the announcement & & & & & \\
effects =0 & & & & 0.20 & 0.66 \\
QE1 & 0.54 & 0.88 & 0.80 & 0.18 & 0.84 \\
QE2 & 0.38 & 0.48 & 0.51 & 0.16 \\
QE3 & 0.00 & 0.06 & 0.00 & 0.00 & 0.16 \\
\hline
\end{tabular}

Sources: Author's regressions.

a. Standard errors are in parentheses.

LSAP announcements into the 5 days that correspond to QE1, the first 2 days of QE2, and the more recent announcement that constitutes QE3.

Table 1 shows the results of this regression analysis for each of the top five financial holding companies. The table reports estimated coefficient values for the current and lagged effects of the announcement for QE1, QE2, and QE3, along with the standard errors of the coefficients. I also report the adjusted $R^{2}$ of the regression and the probability value associated with the $F$ test that the sum of contemporaneous and lagged announcement coefficients is equal to zero for each LSAP program.

The results provide statistical confirmation of the findings displayed in figure 2. There is no statistically significant effect of the LSAP announcements on the 5-year CDS rates of these companies for either QE1 or QE2. The effect of the QE1 announcements is negative but quantitatively small: the median impact across the five companies is -3 basis points. The effect of the QE2 announcements is positive and not as trivial in magnitude: the 
Table 2. Regressions Estimating the Effect of Changes in Treasury Yields on CDS Rates of Large Financial Holding Companies ${ }^{a}$

\begin{tabular}{lccccc}
\hline & \multicolumn{5}{c}{ Company } \\
\cline { 2 - 6 } & & & \multicolumn{2}{c}{ JP } \\
Independent variable & America & Citigroup & $\begin{array}{c}\text { Goldman } \\
\text { Sachs }\end{array}$ & $\begin{array}{c}\text { Morgan } \\
\text { Chase }\end{array}$ & $\begin{array}{c}\text { Morgan } \\
\text { Stanley }\end{array}$ \\
\hline Change in 5-year & -0.41 & -0.82 & -0.74 & -0.35 & -1.41 \\
$\quad$ Treasury yield & $(0.04)$ & $(0.08)$ & $(0.08)$ & $(0.03)$ & $(0.17)$ \\
$R^{2}$ (no. of observations & 0.09 & 0.11 & 0.09 & 0.15 & 0.07 \\
$\quad=917$ ) & & & & & \\
\hline
\end{tabular}

Source: Author's regressions.

a. Standard errors are in parentheses.

median impact is +11 basis points. Finally, the effect of the QE3 announcement is positive and large: the median impact is +52 basis points. This last finding appears consistent with the authors' conjecture that other news events may have contaminated the results for the QE3 announcement. It may also reflect the market's reassessment of the economic outlook given the announced size of the program.

To further investigate why the LSAP programs had either zero or a positive effect on the CDS rates of these companies, I first consider the effect of changes in Treasury rates on the 5-year CDS rate on nonannouncement days. I regress the 1-day change in the 5-year CDS rate of financial holding companies on the 1-day change in the 5-year Treasury yield, using the full sample but dropping days on which LSAP announcements occurred. Regressions are again estimated for each financial holding company separately. The results, reported in table 2 , highlight a strong negative relationship between changes in Treasury rates and changes in the CDS rates of the five companies over this period. Although the coefficients vary across companies, the effect is always statistically significant and economically large: a 1-percentage-point reduction in the 5-year Treasury rate implies an increase in CDS rates of between about 40 and 140 basis points. These results are highly robust to using either the 1-year or the 10-year Treasury rate instead of the 5-year Treasury rate (results not shown).

This negative relationship between the CDS rates of financial holding companies and the level of interest rates is consistent with the notion that financial intermediaries experience a decline in net income in the short run when interest rates fall. Such an effect is well documented in recent work by William English, Skander Van den Heuvel, and Zakrajšek (2011), who consider the effect of surprise movements in interest rates on the net 
income and stock market values of financial intermediaries during the precrisis period. According to their analysis, a reduction in the overall level of Treasury rates reduces these intermediaries' net income in the short run. It also leads to an expansion of their assets over time, which eventually produces a small positive long-run effect on their net income. The long-run expansionary effect implies that a reduction in Treasury rates has a positive effect on these companies' stock market value. Thus, in normal times, one would expect that a reduction in Treasury rates represents good news for financial firms and should lead to both an increase in their stock market values and a reduction in their default risk as measured by CDS spreads.

During a financial crisis, however, it is unlikely that the expansion option has much value. Thus, one possible explanation for the systematically negative relationship between financial sector CDS rates and Treasury rates documented in table 2 is that the negative effect on net income in the short run raised the default probability of financial firms during the crisis period.

To the extent that the relationship between changes in Treasury rates and changes in the CDS rates of financial holding companies is causal (I return to this issue below), it is reasonable to consider whether LSAP announcements have an effect on the default risk of the same financial holding companies once one controls for the usual relationship between CDS rates and Treasury rates that occurs throughout this period. Accordingly, for each financial holding company, I construct the estimated residual $\left(\varepsilon_{t, c d s}=\Delta \operatorname{CDS}_{5 y r}-\hat{\alpha}_{0}-\hat{\alpha}_{1} \Delta \operatorname{Treas}_{5 y r}\right)$ implied by the regression estimated in table 2. I then regress this residual on a set of indicator variables for LSAP announcement dates. For simplicity, I consider only the contemporaneous effect of the 1-day announcement on the contemporaneous residual, omitting the lagged effects reported in table 1. (I obtain similar results, not shown, when allowing for lagged announcement effects.)

The results, reported in table 3, show that QE1 announcements have a negative effect on the CDS residuals for all of the five large financial holding companies except Citigroup. For the four other companies, the announcements imply an average reduction in $\varepsilon_{t, c d s}$ that varies between -9 and -34 basis points. This effect is statistically significant at the 5 percent level or greater for all four firms. For Citigroup, the QE1 announcement effect is statistically indistinguishable from zero. The effect of QE2 is both economically small and statistically insignificant for all financial holding companies. As in the levels regressions reported in table 1, the effect of the QE3 announcement is again positive, large, and statistically significant for all the financial holding companies except Morgan Stanley. Overall, these 
Table 3. Regressions Estimating the Effect of LSAP Announcements on CDS Residuals ${ }^{\mathrm{a}}$

\begin{tabular}{|c|c|c|c|c|c|}
\hline \multirow[b]{2}{*}{ Announcement } & \multicolumn{5}{|c|}{ Company } \\
\hline & $\begin{array}{l}\text { Bank of } \\
\text { America }\end{array}$ & Citigroup & $\begin{array}{l}\text { Goldman } \\
\text { Sachs }\end{array}$ & $\begin{array}{c}J P \\
\text { Morgan } \\
\text { Chase }\end{array}$ & $\begin{array}{l}\text { Morgan } \\
\text { Stanley }\end{array}$ \\
\hline QE1, current effect & $\begin{array}{l}-0.10 \\
(0.05)\end{array}$ & $\begin{array}{c}0.00 \\
(0.08)\end{array}$ & $\begin{array}{l}-0.16 \\
(0.08)\end{array}$ & $\begin{array}{l}-0.09 \\
(0.03)\end{array}$ & $\begin{array}{l}-0.34 \\
(0.18)\end{array}$ \\
\hline QE2, current effect & $\begin{array}{l}-0.01 \\
(0.07)\end{array}$ & $\begin{array}{c}0.02 \\
(0.13)\end{array}$ & $\begin{array}{l}-0.02 \\
(0.12)\end{array}$ & $\begin{array}{c}0.00 \\
(0.04)\end{array}$ & $\begin{array}{l}-0.11 \\
(0.29)\end{array}$ \\
\hline QE3, current effect & $\begin{array}{c}0.43 \\
(0.10)\end{array}$ & $\begin{array}{c}0.32 \\
(0.18)\end{array}$ & $\begin{array}{c}0.31 \\
(0.17)\end{array}$ & $\begin{array}{c}0.16 \\
(0.06)\end{array}$ & $\begin{array}{c}0.34 \\
(0.40)\end{array}$ \\
\hline $\begin{array}{l}R^{2} \text { (no. of observations } \\
\quad=925)\end{array}$ & 0.09 & 0.00 & 0.06 & 0.02 & 0.07 \\
\hline
\end{tabular}

Source: Author's regressions.

a. Standard errors are in parentheses.

results suggest that the QE1 announcements had a strong negative impact on the default risk of large financial holding companies, once one controls for the overall negative relationship between CDS rates and the level of interest rates prevailing during this period.

Regressing CDS rates or the CDS residual on LSAP announcement days provides an indication of whether LSAP announcements influenced the default risk of financial holding companies, but it does not directly determine how much CDS rates respond to a given movement in Treasury yields that is engineered by LSAP announcements. Understanding this quantitative mechanism is particularly important given that different programs affected Treasury rates differently. To consider the quantitative relationship between financial intermediary default risk and Treasury yields, I therefore turn to an instrumental variables regression. I regress the contemporaneous residual $\varepsilon_{t, c d s}$ on the contemporaneous change in the 5-year Treasury rate, using the QE announcements as instruments. Here I include three sets of instruments: the indicators for whether there was an LSAP announcement associated with each of the three QE episodes. This procedure is equivalent to regressing the change in the 5-year Treasury rate on QE1, QE2, and QE3 announcements, obtaining the fitted value, and then regressing the CDS residual on this fitted value. The results of this equation, estimated for each financial holding company using two-stage least squares, are reported in table 4. Small-sample, robust standard errors are reported along with the $R^{2}$ from the second-stage regression.

The results in table 4 imply that the predicted changes in the 5-year Treasury yield owing to LSAP announcements have a significant effect 
Table 4. Instrumental Variables Regressions of CDS Residuals on the Change in the 5-Year Treasury Yield ${ }^{\mathrm{a}}$

\begin{tabular}{lccccc}
\hline & \multicolumn{5}{c}{ Company } \\
\cline { 2 - 6 } & Bank of & & Goldman \\
Independent variable & America & Citigroup & $\begin{array}{c}\text { Morgan } \\
\text { Shase }\end{array}$ & $\begin{array}{c}\text { Morgan } \\
\text { Stanley }\end{array}$ \\
\hline Change in 5-year & 0.56 & 0.84 & 0.83 & 0.83 & 1.81 \\
$\quad$ Treasury yield & $(0.25)$ & $(0.22)$ & $(0.24)$ & $(0.24)$ & $(0.44)$ \\
$R^{2}$ (no. of observations & 0.09 & 0.11 & 0.09 & 0.15 & 0.07 \\
$\quad=925)$ & & & & & \\
\hline
\end{tabular}

Source: Author's regressions.

a. Standard errors are in parentheses.

on $\varepsilon_{t, c d s}$, the residual default risk of large financial holding companies. In particular, calculating the median effect across the five banks, I find that a 1-percentage-point decrease in the 5-year Treasury rate due to an LSAP announcement implies an 83-basis-point reduction in the 5-year CDS rate residual. The estimated effect varies from a low of 56 basis points for Bank of America to a high of 181 basis points for Morgan Stanley. In all cases the coefficient on the 5-year Treasury rate is statistically significant at the 5 percent level or greater.

In summary, the regressions imply that the effect of LSAP announcements on the default risk of the top five financial holding companies is zero for QE1 announcements, slightly positive for QE2 announcements, and positive and statistically significant for the QE3 announcement. These estimates combine two effects: an effect operating through the average relationship between CDS rates and Treasury rates during the financial crisis, and the additional effect of the $\mathrm{QE}$ announcement itself. Controlling for the former, I find a strong positive relationship between changes in Treasury rates engineered by LSAP announcements and the default risk of large financial holding companies.

As discussed above, one interpretation of these results is that during the financial crisis, a reduction in Treasury yields had negative consequences for the net income of financial firms. The decline in net income caused their CDS rates to rise. Following LSAP announcements, this negative effect was offset by an additional positive effect specific to the LSAP program. This may be due to the fact that LSAP purchases include mortgage-backed securities and other assets that are specific to financial sector balance sheets. It may also be due to the fact that the LSAPs reduced overall default risk in the economy, which is positively reflected in the CDS rates of financial 
intermediaries, once one controls for the negative effect of changes in the level of interest rates on financial sector default risk that was prevalent during this period.

An alternative interpretation, however, is that the negative relationship between the CDS rates of financial holding companies and Treasury rates largely reflects a flight-to-quality mechanism. In this view, both Treasury rates and CDS rates respond simultaneously to economic events that trigger a flight to the safer asset: CDS rates rise while Treasury rates fall. In this view the negative relationship is not due to one acting on the other, but rather reflects broader asset pricing forces at work during the financial crisis. Roughly speaking, on nonannouncement days, shocks that trigger a flight to quality predominate, and the negative relationship is observed. On announcement days, however, these shocks are likely less relevant or nonexistent. Under this interpretation, a regression of the CDS rates on LSAP announcements provides the correct gauge of the effect of LSAP programs on financial intermediary default risk, and one would therefore conclude that LSAP announcements had no direct effect on reducing that risk. Assessing the extent to which either of these views provides a coherent explanation for the lack of direct evidence linking LSAP announcements to changes in the default risk of financial intermediaries requires further detailed investigation.

\section{REFERENCES FOR THE GILCHRIST COMMENT}

Adrian, Tobias, Emanuel Moench, and Hyun Song Shin. 2010. "Financial Intermediation, Asset Prices, and Macroeconomic Dynamics.” Staff Reports no. 422. Federal Reserve Bank of New York. (January).

English, William, Skander Van den Heuvel, and Egon Zakrajšek. 2011. "Interest Rate Risk and Bank Equity Valuations." Working paper. Washington: Board of Governors of the Federal Reserve.

Gilchrist, Simon, and Egon Zakrajšek. 2011. "The Effects of Large Scale Asset Purchases on Financial Sector Risk." Working paper. Boston University.

He, Zhiguo, and Arvind Krishnamurthy. 2010. "Intermediary Asset Pricing." Working paper. Northwestern University.

\section{COMMENT BY}

THOMAS PHILIPPON There was a time when macroeconomic textbooks used only one interest rate. The focus on one rate rested on the idea of integrated financial markets and constant relative risks. In such a world, monetary policy needed only to ensure price stability, not financial stability. On the empirical side, much work was done to demonstrate the impact 
of monetary policy on inflation and output (see, for example, the classic contribution of Romer and Romer 2004).

The crisis that started in 2007 has shown that financial markets can quickly become segmented and has forced us to rethink the role of monetary policy. This excellent contribution by Arvind Krishnamurthy and Annette Vissing-Jorgensen provides the evidence that is needed to test the next generation of macrofinance models. Their paper leads us to think about exactly which markets are segmented and why this matters for policy.

The two main contributions of the paper are, first, the use of intraday data to improve identification, and second, the study of a large set of yields and spreads in an effort to understand the channels through which unconventional monetary policy affects the economy. I personally find the expression "quantitative easing" (QE) confusing, but given its widespread use, I will stick to it and refer to QE1 and QE2. I will focus on three issues:

-why one might not expect a duration risk channel to have been operating in the circumstances of late 2008 and early 2009

-why the credit risk channel matters so much for firms and for households, and

- why it is hard to identify liquidity and safety effects in the case of agency bonds.

I will conclude with a brief discussion of policy implications.

THE DURATION RISK CHANNEL (OR LACK THEREOF) An interesting finding of the paper is that a reduction in duration risk does not seem to play an important role in the transmission mechanism of QE. One possible interpretation is that the duration risk premium was small during the financial crisis. This would be consistent with standard theory if investors in 2008 were more worried about demand shocks (that is, debt deflation) than about supply shocks (from oil or technology). To see why, start from the standard bond pricing formula. The price $P_{t}^{(\tau)}$ at time $t$ of a zero-coupon bond with maturity $\tau$ solves the following recursive equation:

$$
P_{t}^{(\tau)}=\mathrm{E}_{t}\left[m_{t+1} P_{t+1}^{(\tau-1)}\right]
$$

where $m_{t+1}$ is the one-period pricing kernel (between $t$ and $t+1$ ), and the terminal condition $P^{(0)}=1$. For $\tau=1$ the definition of the short-term rate becomes $e^{-r, t}=\mathrm{E}_{t}\left[m_{t+1}\right]$. For $\tau=2$ it is

$$
P_{t}^{(2)}=e^{-r, t} \mathrm{E}_{t}\left[e^{-r, t+1}\right]+\operatorname{cov}_{t}\left[m_{t+1} ; e^{-r, t+1}\right] .
$$


The yield curve slopes upward if long-term bonds are riskier than shortterm bonds. This depends on the covariance between $m$ and the future short-term rate. Bad news corresponds to high values of $m$. If the Federal Reserve increases the short-term rate in response to bad news, then $\operatorname{cov}_{t}$ $\left[m_{t+1} ; e^{-r, t+1}\right]<0$, the price of the 2 -year bond is reduced, and the yield curve slopes upward (for more on this, see Piazzesi and Schneider 2006).

Since the Federal Reserve increases the short-term rate in response to inflation, the question boils down to the following: is inflation bad news or good news? In normal times, one would expect inflation to be mostly bad news (oil price shocks, negative productivity shocks, and the like). But in the circumstances of 2008-09, one might conjecture that investors were mostly worried about deflation triggered by a credit crunch (Midrigan and Philippon 2010, Eggertsson and Krugman 2011). In this case inflation would actually be good news, and long-term bonds would provide a hedge against deflation risk.

It follows that if deflation risk dominates, one should not expect a significant duration risk premium. This might explain why the authors do not find that $\mathrm{QE}$ affected the economy by reducing duration risk.

CREDIT RISK The authors find remarkably strong effects of QE announcements on credit risk. At the corporate level, credit spreads are a key driver of corporate investment (Philippon 2009, Gilchrist and Zakrajšek 2011). My figure 1, taken from Philippon (2009), illustrates this point. It shows the investment rate (capital expenditure divided by the capital stock) and a measure of Tobin's $q$ constructed from bond prices.

A simple back-of-the-envelope calculation will be useful here. Krishnamurthy and Vissing-Jorgensen find that QE1 lowered the spread on 5 -year CDSs of Baa-rated borrowers by 51 basis points (bp). From the calibration in Philippon (2009), this implies an increase in the investment rate of about $50 \mathrm{bp}$. Since $I / K$ is 0.1 , this means that investment increased by about 5 percent thanks to QE1. Seen in this light, QE1 appears to have been an unmitigated success.

Credit risk also matters for households. This recession was unique in the sense that household balance sheets were severely affected, whereas corporate balance sheets remained relatively strong. Consider the yields on asset-backed securities (ABSs) collateralized by consumer credit (for example, credit card ABSs). The declines in yield for these securities were significant for QE1 (60 bp), but not for QE2 (3 bp). ${ }^{1}$ For QE1 the impacts

1. I thank the authors for providing the data. The ABS series is from Barclays (obtained via Datastream) and has a duration of 3 to 4 years. 
Figure 1. Bond Market $q$ and Corporate Investment, 1950-2006

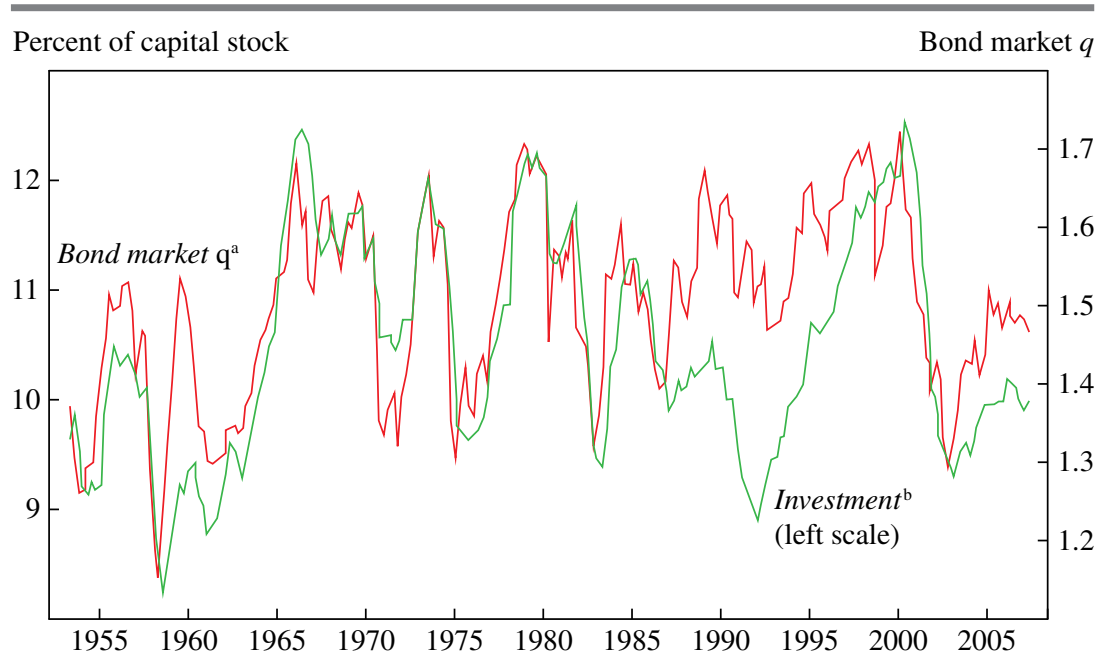

Source: Philippon (2009).

a. Constructed from Moody's yield on Baa bonds, using the structural model described in Philippon (2009) calibrated to observed values for book leverage and firm volatility, expected inflation from the Livingston survey, and the yield on 10-year Treasury bonds.

b. Corporate fixed investment divided by the replacement cost of equipment and structure.

fall in between that on Treasury and that on agency yields. For QE2 the impact is essentially nil.

AGENCY BONDS AND THE LIQUIDITY CHANNELS For QE1 the authors find that 10 -year agency yields fall by $200 \mathrm{bp}$, a large number. By comparison, 10-year Treasury yields fall by about $100 \mathrm{bp}$, and the signaling channel explains about $40 \mathrm{bp}$ of the change in Treasury yields. The authors compare agency yields with Treasury yields in order to isolate a liquidity channel, and agency yields with prices on 2-year federal funds futures to isolate a safety channel.

The issue is how much one can learn from these comparisons. Their validity relies on agency bonds being as free of credit risk as Treasury bonds. However, the view in the finance industry is not as clear-cut as the authors'. For instance, Fidelity Investments describes agency bonds to its investors as follows: "[Government-sponsored enterprise] and agency bonds generally offer yields slightly higher than U.S. Treasuries . . . their credit risk does not have the unconditional backing of the U.S. government." If this

2. Fidelity.com, "Agency Bonds" (www.fidelity.com/bonds/agency-bonds), under "Features \& Benefits." 
Figure 2. Yields on Consumer Credit ABSs, January 2007-September 2011

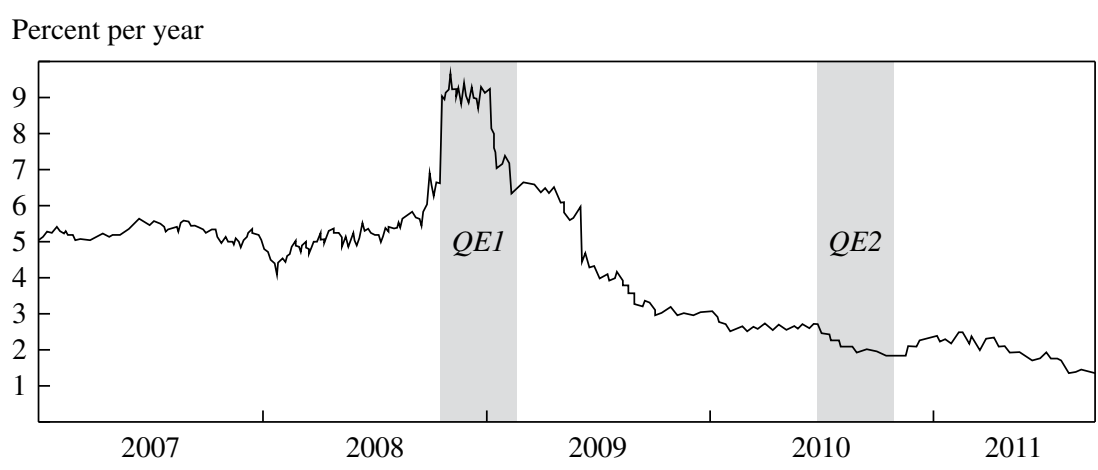

Source: Barclays (via Datastream).

is typical of views in the industry, it does not seem that investors expect agency bonds to be free of credit risk. A move by the Federal Reserve to buy large quantities of agency bonds would therefore be expected to lower the perceived credit risk. As a consequence, the authors probably overestimate the size of the safety and liquidity channels. That said, however, it seems unlikely that changes in perceived credit risk could explain a relative move of 100 basis points. It seems clear that liquidity issues were significant, but perhaps not quite as large as the authors' calculations suggest.

CONCLUSION AND POLICY IMPLICATIONS There should be no doubt that this paper provides a fantastic set of stylized facts for future research in macroeconomics and finance. It also provides an insightful discussion of the various channels through which unconventional monetary policy can affect the economy.

On the policy side, one naturally needs to acknowledge that not enough is yet known to make clear recommendations. Suppose, for instance, that QE works mainly by avoiding a disastrous debt deflation spiral, with massive defaults by consumers and firms. In that case one can almost think of $\mathrm{QE}$ as moving the economy away from a bad equilibrium. One would certainly expect all risks and liquidity premiums to be globally affected, even if the main channel is, say, credit risk. The point here is that, in general equilibrium, there might not be clear distinctions between the various channels that the authors consider.

This is also important when comparing QE1 and QE2. Figure 2 shows the full daily series from January 2007 to September 2011 of the consumer credit ABS yields discussed earlier. The periods surrounding QE1 and QE2 
are highlighted. It is clear that QE1 took place at a time of extremely high and volatile yields, probably reflecting acute concerns about consumer credit risk. If the main effect of $\mathrm{QE}$ is to save the economy from a bad equilibrium, it seems that QE2 had no chance to have worked as well as QE1, not because QE2 failed to target mortgage-backed securities, but rather because the world does not need to be saved every year.

\section{REFERENCES FOR THE PHILIPPON COMMENT}

Eggertsson, Gauti, and Paul Krugman. 2011. "Debt, Deleveraging, and the Liquidity Trap: A Fisher-Minsky-Koo Approach.” Working paper. Princeton University.

Gilchrist, Simon, and Egon Zakrajšek. Forthcoming. "Credit Spreads and Business Cycle Fluctuations." American Economic Review.

Midrigan, Virgiliu, and Thomas Philippon. 2010. "Household Leverage and the Recession.” Working Paper no. 16965. Cambridge, Mass.: National Bureau of Economic Research.

Philippon, Thomas. 2009. "The Bond Market's q." Quarterly Journal of Economics 124: 1011-56.

Piazzesi, Monika, and Martin Schneider. 2006. "Equilibrium Yield Curves." In NBER Macroeconomic Annual, edited by Daron Acemoglu, Kenneth Rogoff, and Michael Woodford. MIT Press.

Romer, David, and Christina Romer. 2004. "A New Measure of Monetary Shocks: Derivation and Implications." American Economic Review 94, no. 4: 1055-84.

GENERAL DISCUSSION Robert Shiller wondered how to interpret the results of the event study given the newness and uniqueness of QE2. Most event studies examine types of events that have occurred repeatedly over decades, and they largely measure the reaction of intraday traders to an event. These traders, he argued, act not on their own beliefs about the ultimate meaning of the new information, but rather on their guess as to how other investors will react. These guesses might be very unstable when a new kind of event occurs. Shiller thought it would be interesting to conduct a meta-analysis of event studies to see how often the results of the first 10 or so events of each kind are borne out by later evidence.

Having worked in investment banking for some 20 years, Douglas Elliott found the paper's results quite plausible, but he agreed with Shiller that it is difficult to interpret yield movements generated primarily by intraday trading. Noting the authors' result that B-rated credit default swap rates fell a cumulative 768 basis points in the event windows considered for QE1, while Ba-rated corporate bond credit default swap rates fell only 84 basis 
points, Elliott doubted that the large difference could be fully attributed to the default risk channel, as the authors suggested.

Finally, Elliott agreed with Thomas Philippon that markets do not see agency bonds as having the same minimal credit risk as Treasuries. However, he did not think the difference in risks was large enough to change the paper's conclusions significantly. Annette Vissing-Jorgensen responded that the agencies had been taken under conservatorship by the federal government in September 2008. One might argue that this rescue was not credible, but, unfortunately, she and Krishnamurthy could not test how markets interpreted the intervention, because credit default swaps on the agencies had ceased trading.

Edward Lazear thought that to understand the effects of QE1 and QE2, it was important to take into account heterogeneity in the preferences and valuations of individual market participants, rather than assume that market participants all react in the same way. In general, he proposed, if an asset is price elastic, then people value that asset similarly, whereas if it is price inelastic, valuations are more heterogeneous. Similarly, if the price effect of an announcement is large, it is likely that people are interpreting that announcement similarly, whereas if it is small, interpretations are likely to be varied. He suspected that heterogeneity in valuations was greater for QE1 because it happened sooner after the height of the financial crisis, before markets had had much time to recover.

Robert Hall proposed that the authors consider the reaction of the Treasury to QE1 and QE2 in assessing the effects of the Federal Reserve's actions. The Treasury does not treat the choice of maturity of the securities it issues as a policy variable, he argued. If it did, it would copy the Federal Reserve and issue more short-term and less long-term debt. Instead, the Treasury has lengthened the maturity of its debt issuance in recent years. The Treasury is influenced, to some extent, by an advisory committee of securities dealers, whose interests may not coincide with those of the Fed.

Vissing-Jorgensen responded that the Treasury's offsetting actions did not compromise the integrity of the event study because the Treasury did not make announcements about plans to lengthen the maturity of its debt on the same days as the Federal Reserve's announcements related to QE2. For judging the longer-term net impact of QE2, however, she agreed that the Treasury's reaction was important.

David Wessel found it interesting that the Treasury has been lengthening the maturity of its debt at a time when the Federal Reserve has been going in the opposite direction. As he understood it, the maturity of Treasury debt 
issuances was also an issue during Operation Twist in the 1960s, when the Federal Reserve supposedly was coordinating with the Treasury. The current Treasury was emphatic that it was not linking its actions to the Federal Reserve's, and Wessel wondered whether it would continue to lengthen the maturity of its debt-which is currently above average-if the Federal Reserve announced a new Operation Twist. He also wondered whether it made any sense for the Federal Reserve to contemplate a repeat of Operation Twist, which only reduces duration risk, given the paper's result that duration risk is unimportant.

Michael Woodford thought it incorrect to characterize the paper's eventstudy effects as those of "quantitative easing" per se. When the term was originally introduced during discussions of the Bank of Japan's policies in the late 1990s and early 2000s, it referred specifically to the idea of stimulating the economy through growth in the base money supply by increasing the size of the central bank's balance sheet, even in the absence of any effect on short-term interest rates. In contrast, the paper found that the effects of QE2 stemmed more from the change in relative supplies of safe and risky assets than from growth in the monetary base. The importance of the asset mix channel suggested to Woodford that the Treasury should complement the Federal Reserve's actions by introducing its own policies that shift the relative supply of safe and risky assets.

Woodford also commented on the signaling channel: although the paper suggested that the Federal Reserve's announcements of asset purchases had signaling effects, he did not think that these announcements were, in general, a good way to achieve such effects. The effect of asset purchases on the future path of interest rates and of inflation is highly context dependent, and so the signal sent by the announcement is subject to uncertainty and varies with outside conditions. Announcements about policy targets and commitments to future policies, as opposed to announcements about asset purchases, have clearer implications for the future path of interest rates and therefore are likely to have more reliable signaling effects.

Randall Kroszner cautioned that the efficacy of the signaling effect did not give central banks the opportunity to affect markets just by making announcements about policy without following through on their commitments. Such a plan could only work once before costing the central bank all of its credibility.

Frederic Mishkin agreed with Woodford that quantitative easing by the usual definition - that is, balance sheet expansion —-was not the key feature of the recent interventions by the Federal Reserve. He thought that the signaling effects of the interventions were much more important, and he noted 
that Chairman Bernanke had repeatedly said that the Federal Reserve was engaging in credit easing, not quantitative easing. Mishkin thought a key conclusion of the paper was that actions in credit markets, and signaling in particular, had a much greater impact than balance sheet expansion. $\mathrm{He}$ cited the related example of the Bank of Japan's balance sheet expansions in the early to mid-2000s, which, he argued, had not worked to lower Japanese interest rates. The reason, in his view, was that the Bank of Japan had simultaneously expressed its wish to raise interest rates toward normal levels, and this signal overrode whatever effect the quantitative easing might have had on yields.

Finally, Mishkin offered the caveat that for a signal to be credible, the central bank issuing it must do something that is costly. He saw the Federal Reserve's recent move as politically very costly-for example, it had led to strident criticism from some of the current candidates in the 2012 presidential race-which led him to wonder whether the Federal Reserve could find a way of making its signals credible without expanding its balance sheet.

Woodford agreed that the issue of whether balance sheet changes or other Federal Reserve actions could actually make its signals more credible was important, but it was not clear to him that its recent actions had added credibility to a signal, or that they were even meant to do so. In fact, before QE2, the Federal Open Market Committee had considered an alternative option of providing more clarity about future policy targets-in other words, more direct signaling. He thought the committee had ultimately opted for asset purchases specifically because they would have their own, real effects that did not require the Federal Reserve to discuss their implications for future policy.

Ricardo Reis worried that the discussion about signaling overlooked the fact that a single balance sheet change could be interpreted as a signal of different, and sometimes contradictory, intentions. For instance, when the Federal Reserve decides to accumulate long-term bonds, in some circumstances that could be seen as trying to help lift the economy out of a liquidity trap and raise inflation. Alternatively, if observers think the Federal Reserve is worried about its accounting capital (whether or not that is the case), then long-term bond accumulation could be seen as a signal that it will pursue lower inflation, since higher inflation would result in large capital losses for the Fed. Because asset purchases can be interpreted in these different ways, Reis argued, for signaling to be most effective, the Federal Reserve should opt for explicit interest rate or price-level targets.

Joseph Gagnon said he had considered doing an event study on QE2 and had concluded that it would be impossible; he therefore congratulated 
the authors for conducting this study and managing to obtain some sensible results. However, he was concerned that the study omitted a number of dates on which yields seemed to have moved substantially in response to related events. For example, yields fell following a July 29 speech by St. Louis Federal Reserve Bank President James Bullard and an early August speech by the former secretary of the Federal Open Market Committee, Vincent Reinhart. Chairman Bernanke's speech at Jackson Hole on August 26 also attracted a lot of attention and could have affected yields. Beyond these dates, there were many others on which journalists attributed yield movements to changing views about the likelihood of QE2. Without attributing too much importance to these claims, Gagnon argued, one must still accept that, unlike with QE1, investors had a long time to speculate about the likelihood of the Federal Reserve pursuing QE2 and react accordingly. In the event, when QE2 was actually announced, it seemed that investors had overreacted to the possibility of QE2, and over the next couple of weeks their expectations unwound. Although the authors' results turned out to be close to what Gagnon would have predicted given the size of QE2 and estimates of the effects of previous similar events, the number of dates with sizable yield moves that were excluded from the sample led him to question the credibility of their findings.

David Wessel shared Gagnon's concern about the limited number of dates included in the study, particularly because nowadays the press frequently reports news about possible future actions of the Federal Reserve. For example, Wessel's colleague at the Wall Street Journal, Jon Hilsenrath, had recently written a story asserting that the Federal Reserve would probably move to reinvest in mortgage markets. Wessel seconded the point that investors saw Bernanke's Jackson Hole speech as a significant signal.

Vissing-Jorgensen responded that she and Krishnamurthy had, in fact, looked at intraday data for a number of other possible QE2-related events, including Bernanke's Jackson Hole speech. Within minutes of that speech, yields actually rose, whereas for some other speeches, yields did not move much within that time frame. Moreover, she was not sure how to interpret the reaction to the Jackson Hole speech, since it essentially only reviewed a list of advantages and disadvantages of $\mathrm{QE}$.

Gagnon was also hesitant to draw any conclusions about the impact of QE2 on mortgage-backed securities from the one-day movement of their yields on the two event days examined in the study. In his own research he had found this market to be quirky and slow to react: during QE1, it had been the only market in which actual asset purchases by the Federal Reserve moved yields even when those purchases had been announced in 
advance. In the markets for Treasuries and agency bonds, yields moved on the days the Federal Reserve announced its asset purchase plans, but not on the days when they were executed, presumably because those purchases had already been fully incorporated into investors' expectations.

Finally, Gagnon questioned the conclusion that the most important channel of QE2 was a pure safety effect. The authors had come to this conclusion by arguing that high-grade corporate bonds are, in terms of safety, the most similar to Treasuries, and during QE2 their yields fell more than those of other, less safe assets. But if the term-length channel was unimportant, Gagnon asked, why did Treasury bond yields fall more than Treasury bill yields during QE2? After all, the only difference between these assets is their term length.

Vissing-Jorgensen said she and Krishnamurthy did not disagree with Gagnon that there was a term effect: intermediate- and long-term yields did move much more than Treasury bill yields. Where she and Krishnamurthy disagreed was in interpreting this effect as a duration risk premium. Instead, she thought the term effect should be thought of as revealing a preferred habitat demand for medium- to long-term assets. The distinction was important, she felt, because if there is a pure duration risk premium, buying any type of long-term assets will move all long-term yields, whereas if the long-term preference is specific to safe assets, then buying long-term Treasuries will disproportionately move Treasury yields.

Randall Kroszner thought that to understand the kinds of policies undertaken by the Federal Reserve, it was important to consider the impact of the tail risk, since it could affect assets in ways not fully understood and which could be nonlinear. Kroszner was also struck by the fact that QE had led to an increase in inflation expectations, but a reduction in interest rate volatility, since usually interest rate volatility rises with inflation expectations. He thought this unusual pattern suggested that the intervention did have the effect of reducing tail risk.

Kroszner also responded to Gilchrist's comment about the impact of the Troubled Asset Relief Program (TARP) on financial markets. He thought that the date of the bill's passage, October 3, 2008, was not as significant as October 14, the date on which Treasury Secretary Henry Paulson and President Bush announced that TARP would feature an injection of capital into financial institutions and a liquidity guarantee program. This announcement had a large impact on market expectations.

William Brainard suggested that the authors look further into the role of reserves in the liquidity channel. He thought it important to distinguish between different types of reserves, for example between excess reserves 
and reserves that correspond to increases in the liabilities of institutions, to understand how they affect liquidity and the price of liquidity.

Michael Kiley pointed out that the persistence of the effects of the Federal Reserve's policy interventions mattered hugely in determining its impacts. He cited a policy brief written by Jeffrey Fuhrer and Giovanni Olivei at the Federal Reserve Bank of Boston, which estimated that Federal Reserve asset purchases that led to a 100-basis-point reduction in 10-year Treasury yields for two years would raise GDP growth by about 2.5 percentage points. He wondered how confident one could be in the persistence of the effects measured over the two-day horizons in the event study, and he thought it might be worthwhile to investigate how that persistence might differ across the signaling, safety, liquidity, and duration channels.

Ricardo Reis proposed organizing QE2's channels of influence into two categories: channels that basically amount to monetary policy-that is, that affect the size of the money supply or expectations thereof-and channels that concern the relative supply of assets. Signaling about the future path of interest rates would fall into the monetary policy category. Changes in duration risk and default risk would fall into the category of relative asset supply channels. Reis suggested conducting an event study of announcements by the Treasury over the last 20 years in which it said it would lengthen or shorten the maturity of the debt it issues. Since these actions affect only the relative supply of assets, such a study could help separate the effects of relative supply changes from those of monetary expansion.

Jon Hilsenrath highlighted another challenge of event studies, which is that on several of the dates examined, the Federal Reserve announced multiple policy changes at the same time. In March 2009, for example, the Federal Reserve announced both its intention to keep the federal funds rate low for an extended period and its plans to extend its asset purchases. It was unclear to what extent any market reaction was to the low-interestrate commitment and to what extent it was a reaction to the asset purchase announcement. More recently, the Federal Reserve had announced that it would commit to keeping rates low through mid-2013, but also that it was prepared to take further action. Again, was the market response to that announcement more a response to the low-interest-rate commitment or to the possibility of a new policy intervention?

Vissing-Jorgensen accepted Hilsenrath's point and clarified that the signaling effects she and Krishnamurthy were trying to measure could stem from the Federal Reserve's announcements about the federal funds rate, in addition to any signaling effect of QE. 
Arvind Krishnamurthy agreed with Mishkin that it was correct to think of QE1 as credit easing, and not quantitative easing. His own prior was that financial intermediaries' response to QE1 played a significant role in causing yields to fall. He was therefore surprised by Gilchrist's data showing that rates on credit default swaps traded by financial institutions did not change significantly on QE1 event days, since that indicated that QE1 did not have a significant impact on those institutions. This suggested to Krishnamurthy that the channels of credit easing in QE1 required further investigation. Certainly, he thought, if purchases of mortgage-backed securities are affecting their yields, then the risk premium on those securities must be changing. For that to be possible, markets must be segmented or somewhat dysfunctional, which was what had led him to suspect that financial intermediaries were important. Perhaps, however, the effects of QE1 could be operating through some other channel, such as Lazear's hypothesis about heterogeneity in valuations and low elasticity of demand for assets.

Krishnamurthy agreed with Woodford that the signaling effects of QE2 were more important than the asset purchases themselves. Specifically, it was the market's interpretation of the Federal Reserve's actions and its commitment to a future policy path that mattered. Risk premiums are not changing. So, in considering a possible Operation Twist, the evidence from QE2 indicated that changing the maturity structure of debt, in itself, would not have an effect on broad corporate rates, except through signaling.

Krishnamurthy gave an example of how communication alone was enough to move interest rates, and that Treasury purchases were not necessary to achieve results. When the Federal Reserve announced on August, 9, 2011, that it would keep rates low for an extended period, 3-year Treasury rates fell 12 basis points, 5 -year Treasury rates fell 20 basis points, and 10 -year Treasury rates fell 20 basis points-about the same magnitude of effects he and Vissing-Jorgensen had found for QE2.

Finally, Krishnamurthy advised caution in interpreting changes in Treasury yields: these changes are driven by liquidity and safety effects that do not carry over to other asset classes. That meant that even though QE2 had lowered Treasury rates by changing the supply of Treasuries, those rate drops did not necessarily cause credit easing. To determine whether credit easing had actually occurred, one must examine changes in broader rates, such as mortgage rates and corporate bond rates. He and VissingJorgensen had done this and found that drops in these broader rates seemed to correspond much more with the signaling effects of QE2 than changes in Treasury rates caused by Treasury purchases. 
